\title{
Dynamic response and sliding distance of composite breakwaters under breaking and non-breaking wave attack
}

\author{
Giovanni Cuomo ${ }^{1}$, Giorgio Lupoi ${ }^{2}$, Ken-ihiro $^{3}$ Shimosako $^{3}$ \& \\ Shigeo Takahashi ${ }^{4}$
}

\footnotetext{
${ }^{1}$ JSPS Post-Doc Fellow at Maritime Structures Division, Marine Environment and Engineering Department, Port and Airport Research Institute, 3-1-1, Nagase, Yokosuka, Japan 239-0826

Principal Engineer, Coastal Structures Group, HR Wallingford, Howbery Park, Wallingford, OX10 8BA, UK

Principal Coastal Engineer, Hydraulics Applied Research and Engineering Consulting (HAREC) S.r.I. Corso Trieste 142, 00198, Roma, Italy

Corresponding author. F: +44 (0)1491832233 E-mail: g.cuomo@hrwallingford.co.uk

${ }^{2}$ Studio SPERI S.r.I. s.d.i., Lungotevere delle Navi 19, 00196;Roma - Italy

Principal Structural Engineer, Hydraulics Applied Research and Engineering Consulting (HAREC) S.r.I. Corso Trieste 142, 00198, Roma, Italy

F:+390636010310 E-mail: glupoi@studiosperi.it
}

${ }^{3}$ Head of Maritime Structures Division, Marine Environment and Engineering Department, Port and Airport Research Institute, 3-1-1, Nagase, Yokosuka, Japan 239-0826

E-mail: takahashi_s@pari.go.jp

${ }^{4}$ Executive Researcher and Director of Tsunami Research Center, Port and Airport Research Institute, 3-1-1, Nagase, Yokosuka, Japan 239-0826 E-mail address: shimosako@pari.go.jp

Published in: Coastal Engineering, Volume 58, Issue 10, October 2011, DOI: 10.1016/j.coastaleng.2011.03.008

\section{Abstract}

Over the last 15 years improved awareness of wave impact induced failures has focused attention on the need to account for the dynamic response of maritime structures to wave impact load. In this work a nonlinear model is introduced that allows evaluating the effective design load and the potential sliding of caisson breakwater subject to both pulsating and impulsive wave loads. The caisson dynamics is modelled using a time-step numerical method to solve numerically the equations of motion for a rigid body founded on multiple non-linear springs having both horizontal and vertical stiffness. The model is first shown to correctly describe the dynamics of caisson breakwaters subject to wave attack, including nonlinear features of wave-structuresoil interaction. Predictions of sliding distances by the new method are then compared with measurements from physical model tests, showing very good agreement with observations. The model succeeds in describing the physics that stands behind the process and is fast, accurate and flexible enough to be suitable for performance design of caisson breakwaters.

This is the author's version of a work that was accepted for publication in Coastal Engineering. Changes resulting from the publishing process, such as peer review, editing, corrections, structural formatting, and other quality control mechanisms may not be reflected in this document. Change may have been made to this work since it was submitted for publication. A definitive version was subsequently published in Coastal Engineering, Volume 58, Issue 10, October 2011, DOI: 10.1016/j.coastaleng.2011.03.008.

\section{Keywords}

Wave impacts, caisson breakwaters, wave loads, sliding, non-linear dynamics of coastal structures, performance design 


\section{Introduction}

The capability of wave impact loads to cause the sliding of composite-type breakwaters had been proved in the early sixties by Nagai (1966) who stated "It was proven by $1 / 20$ and 1/10 scale model experiments that, at the instant when the resultant of the maximum simultaneous shock pressures just exceeds the resisting force, the vertical wall slides".

Analyses of failures carried out in Europe and Japan over the past 15 years confirm impact loads induced sliding to be the most important cause of failure for caisson breakwaters. Nevertheless, despite the importance of impulsive loadings and their effects on the dynamic of caisson breakwater have been widely recognised, a simple and comprehensive methodology for the assessment of cumulative sliding distance is still missing. This paper presents a simple but consistent method for modelling the dynamic response and sliding distance of composite breakwaters subject to wave attack.

In the following, documented cases of sliding-induced failures of caisson breakwaters are briefly summarised (§ 2.1) and findings from previous researches on dynamics of caisson breakwaters reviewed (§ 2.2-2.3). A non-linear dynamic model for the response of caisson breakwaters subject to wave loading is then presented (§ 3), together with a procedure for the generation of wave force time-histories for use in dynamic analysis (§ 4). The effectiveness of the model is then verified using simplified force time-histories (§ 5) and finally compared to measurements from physical mode tests on sliding of caissons subject to both pulsating and breaking wave attack $(\S 6)$ showing very good agreement with both analytical solutions and experimental observations.

\section{Literature review}

Research on the dynamics of caisson breakwaters subject to wave loading has mainly concentrated on surveying damaged and failed structures, understanding the physics that stands behind the dynamics of caissons and defining wave loads for use in dynamic analysis. Accordingly, in the following we summarise documented failure of caisson breakwaters and most significant efforts towards the understanding of caisson dynamics.

\subsection{Documented Failures}

Oumeraci (1994) gave a review of analysed failure cases for both vertical and composite breakwaters: 17 failure cases were reported for vertical breakwaters and 5 for composite or armoured vertical breakwaters. The author identified wave breaking and breaking clapotis as the most frequent damage source of the disasters experienced by vertical breakwaters, by means of (in order of importance): sliding, shear failure of the foundation and overturning.

Franco (1991 and 1994) and Franco and Passoni (1992) summarised the Italian experience in design and construction of vertical breakwaters giving a historical review of the structural evolution in the last century and critically describing the major documented failures (Catania, 1933; Genova, 1955; Ventotene, 1966; Bari, 1974; Palermo, 1983; Bagnara, 1985; Naples, 1987 and Gela, 1991). In all cases the collapse was found to be due to unexpected high wave impact loading, resulting from the underestimation of the design conditions and the wave breaking on the limited depth at the toe of the structure.

Knowledge on failure mode of vertical breakwaters has been widened by the large experience inherited in recent years from observations made all through last decades in Japan. Among the others, Goda (1974) 
reported ad re-analysed a large number of historical sliding-induced failures of vertical caisson breakwaters in Japan, Hitachi (1994) described the damage of Mutsu Ogawara Port (1991), Takahashi et al. (1994) discussed the failures occurred at Sakata (1973-1974) and Hacinohe (1991) Ports. Takahashi et al. (1998) discussed results from an extensive field survey of Japanese breakwaters and summarised caisson wall failures in the period 1977-1997. Among other findings, the authors confirmed impulsive breaking wave pressure to be the main cause of damage for caisson breakwaters, together with the collision of concrete blocks against the caisson walls. More recently, Takahashi et al. (2000) analysed 33 major failures occurred between 1983 and 1991 and reported typical failures of composite breakwaters; the authors identified sliding of caissons and structural failures due to impulsive wave pressure as the most important failure modes for caisson breakwaters installed on a steep foreshore and subject to breaking wave attack.

\subsection{Existing Models For Dynamics Of Caisson Breakwaters}

Marinski and Oumeraci (1992) gave a review of the CIS (formerly Soviet Union) design experience on dynamic response of vertical structures subject to breaking wave forces. Most of the methods developed in the CIS assumed the dynamics of vertical breakwater to be well described by that of a rigid body on a homogenous, elastic and isotropic half space with the soil parameters adopted in the model driving the overall response of the system. Reviewing the available literature (almost always in Russian), the authors identified three schools of thoughts, based respectively on theoretical works by Petrashen (1956), Smirnov and Moroz (1983) and Loginov (1962 and 1969). The method suggested by Loginov is the only one to have been included in the Russian guidelines for the evaluation of the loadings and their effects on maritime structures; The model combines the swaying and rotating motions of the caisson in two rocking motions around two separate centres (located respectively above and below the centre of gravity of the caisson) and neglects the effect of damping.

De Groot et al. (1996) extensively review (at time) state of the art methods for design of caisson breakwater foundation, including existing approaches to dynamics. On this ground, simplified models for the dynamic behaviour of caisson breakwaters have been developed within the framework of the PROVERBS (PRObabilistic design tools for VERtical BreakwaterS) research project (see, among others, Oumeraci and Kortenhaus, 1994; Oumeraci et al., 1992; Klammer et al., 1994).

Despite its relative simplicity, the model proposed by Oumeraci and Kortenhaus (1994) represents an efficient tool for the exploration of the dynamic response of caisson breakwaters to wave impact loads and a remarkable attempt to quantify the relative importance of the applied dynamic load and the dynamics (mass, stiffness and damping) of the breakwater (including the superstructure, its foundation soil and the surrounding water) on the overall dynamic response of the system as a whole. For these reasons, this model is briefly described in the following.

The rigid body in the idealised 2D lumped system sketched in Figure 1 has two degrees of freedom, respectively the horizontal translation and the rotation around A. For such a system, the equation of motion can be re-written in matrix form as follows:

$$
\mathbf{M} \cdot \ddot{\mathbf{u}}(\mathrm{t})+\mathbf{C} \cdot \dot{\mathbf{u}}(\mathrm{t})+\mathbf{K} \cdot \mathbf{u}(\mathrm{t})=\mathbf{F}(\mathrm{t})
$$

where:

$$
\mathbf{M}=\left[\begin{array}{cc}
\mathrm{m}_{\mathrm{x}} & 0 \\
0 & \mathrm{~m}_{\theta}
\end{array}\right]
$$




$$
\begin{aligned}
& \mathbf{C}=\left[\begin{array}{cc}
c_{x} & c_{x} \cdot\left(H_{c}-y_{A}\right) \\
c_{x} \cdot\left(H_{c}-y_{A}\right) & c_{\theta}+c_{x} \cdot\left(H_{c}-y_{A}\right)^{2}
\end{array}\right] \\
& \mathbf{K}=\left[\begin{array}{cc}
k_{x} & k_{x} \cdot\left(H_{c}-y_{A}\right) \\
k_{x} \cdot\left(H_{c}-y_{A}\right) & k_{\theta}+k_{x} \cdot\left(H_{c}-y_{A}\right)^{2}
\end{array}\right] \\
& \mathbf{F}=\left[\begin{array}{cc}
F_{x}(t) \\
F_{x}(t) \cdot\left(y_{L}-y_{A}\right)+F_{y}(t) \cdot\left(x_{A}-x_{L}\right)
\end{array}\right] \\
& \mathbf{u}=\left[\begin{array}{l}
u_{x}(t) \\
u_{\theta}(t)
\end{array}\right]
\end{aligned}
$$

Terms $m_{x}, m_{\theta}, k_{x}, k_{\theta}, c_{x}, c_{\theta}$ in Equations 2 - 4 represent the total mass $(m)$, the stiffness $(k)$ and the damping ( $c$ ) of the system against sliding $(x)$ and rocking $(\theta)$ and $x_{L}$ and $y_{L}$ are respectively the lever arm of the vertical $\left(F_{y}\right)$ and horizontal $\left(F_{x}\right)$ forces, $x_{A}$ and $y_{A}$ are respectively the coordinates of the centre of rotation of the caisson. According to the authors, the stiffness terms can be determined according to Marinski and Oumeraci (1992) while the total mass of the system is given by the summation of the mass of the caisson, the hydrodynamic mass and the geodynamic mass. The damping coefficients were obtained experimentally by means of pendulum tests on the caisson breakwater model itself and for different degrees of immersion (Oumeraci et al. 1992).
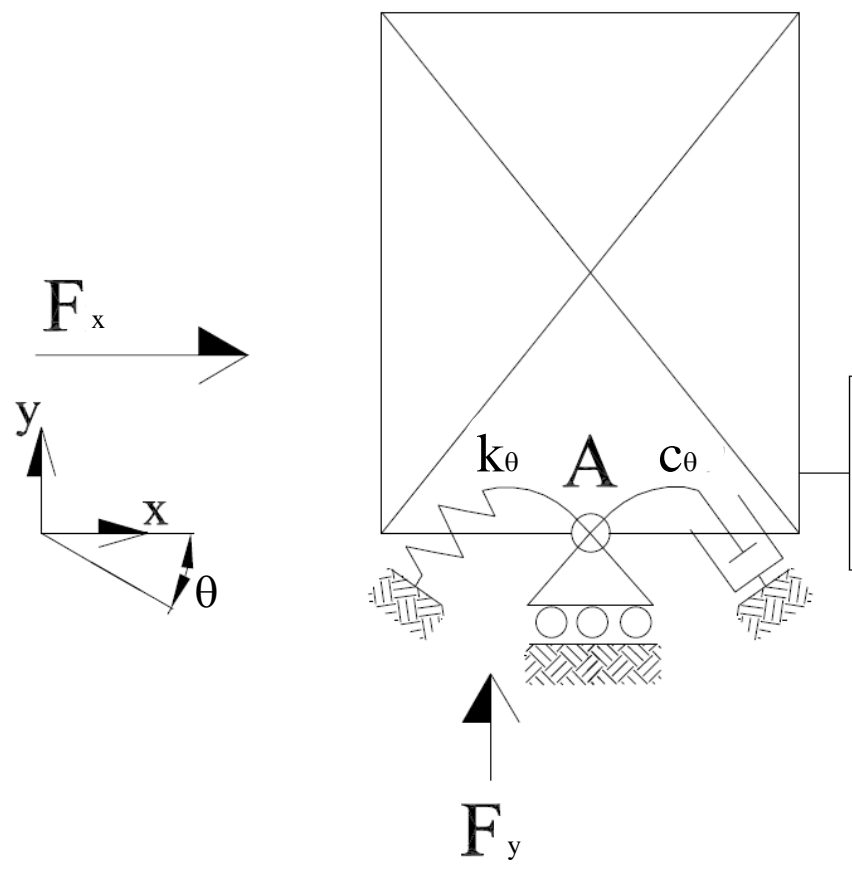

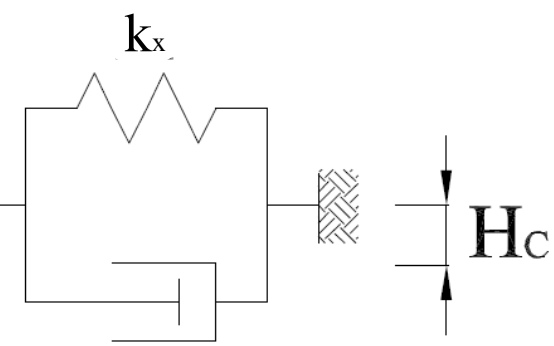

$\mathrm{CX}_{\mathrm{X}}$

\section{Figure $1 \quad$ Dynamic model of caisson breakwater (after Oumeraci and Kortenhaus, 1994)}

Moving from earlier observations during small-scale model tests (Klammer et al. 1994) a simple model for the evaluation of the permanent displacement of caisson breakwaters under impact loads has been suggested by Oumeraci et al. (1995) de Groot et al. (1996) and Kortenhaus and Oumeraci (1996). According 
to the authors, the interaction of the super-structure with the foundation soil is driven by adhesion while the horizontal force does not exceed the critical value $F_{x}$ :

$$
F_{x, c}(t)=\mu_{s} \cdot\left[W-F_{y}(t)\right]
$$

Where $\mu_{s}$ is the static friction coefficient, $W$ is the weight of the caisson in water and $F_{y}(t)$ is the waveinduced uplift force. When the caisson starts to move, a constant friction coefficient $\mu_{d}$ is applied until the horizontal force reduces again to the critical value $F_{x, c}(t)$ in Equation 7 , when the adhesion force starts dominating again.

More recently, the dynamic analysis model proposed by Oumeraci and Kortenhaus (1994) has been extended by Wang (2001) to account for reduction in effective impact forces due to sliding and rocking motion of caisson breakwaters. Among the possible motions of caisson breakwaters under dynamic load, the author distinguished a pure vibrating motion, a vibrating-sliding motion and a vibrating-rocking motion; for each of them, a slightly different version of Equation 1 is proposed which accounts for the relative motion of the caisson and its foundation.

Alternative models have been suggested by researches in Japan. Goda (1994) suggested modelling the dynamics of a composite breakwater as that of a rigid body suspended on a system of mass and dual springs for rotational and horizontal motions, and using the momentum theory of impulsive breaking wave forces to estimate the sliding distance of the superstructure.

Takahashi et al. (1994), investigated the dynamic response and the sliding of breakwater caissons against wave impact loads by mean of a FEM model. A more sophisticated, non-linear model was successively adapted by Takahashi et al. (1998) to evaluate cumulative sliding of caisson breakwater under breaking wave attack. The model was shown to be able to describe the characteristics features of the interaction of the caisson with its soil foundation including sliding; nevertheless, the model was found to be relatively complex and its application time-consuming. Shimosako et al. (1994) and Shimosako and Takahashi (1999) presented a simplified model for the estimation of distance of caisson sliding that was found to compare satisfactorily well with data from small-scale physical model tests. According to the authors, the permanent displacement can be evaluated as:

$$
S=\frac{t_{d}^{2}\left(F_{x, \text { max }}-F_{y, \max }-\mu_{d} \cdot W\right)^{3} \cdot\left(F_{x, \text { max }}-F_{y, \max }+\mu_{d} \cdot W\right)}{8 \cdot \mu_{d} \cdot m_{c} \cdot W \cdot\left(F_{x, \max }-F_{y, \max }\right)^{2}}
$$

Where $t_{d}$ represents the duration of triangular wave thrust, $\mu_{d}$ is the friction coefficient, $W$ is the caisson weight in water, $F_{x, \max }$ is the peak value of wave thrust upon the caisson and $y_{x, \max }$ is the uplift exerted upon the bottom of caisson. The method has been recently adopted in performance-based design (Shimosako and Takahashi, 1999) and reliability design (Goda and Takagi, 2000 and Kim and Takayama, 2003) methods for caisson breakwaters.

An alternative simplified method for the evaluation of the permanent displacement of composite breakwater subject to wave impacts has been presented by Ling et al. (1999). Nevertheless, the method only considers a sinusoidal, long lasting, load and thus suffers from not accounting for the impulsive nature of breaking wave loads.

A summary of the most significant models for dynamics of caisson breakwater proposed in literature is given in Table 1. 
Table 1 Summary of existing models for the dynamics of caisson breakwaters

\begin{tabular}{|c|l|}
\hline $\begin{array}{c}\text { Loinov (1962) } \\
\text { Koda (1994) } \\
\text { (1994) }\end{array}$ & $\begin{array}{l}\text { Swaying and rotating motions are combined } \\
\text { in two rocking motions around two separate } \\
\text { centres. }\end{array}$ \\
\hline $\begin{array}{c}\text { Takahashi et al. } \\
\text { (1994) }\end{array}$ & $\begin{array}{l}\text { Rigid body suspended on a system of mass } \\
\text { and dual springs for rotational and horizontal } \\
\text { motions, includes contribution of the } \\
\text { geodynamic mass. }\end{array}$ \\
\hline
\end{tabular}

\subsection{Existing models for time-history wave loads on caisson breakwaters}

Example time-history load exerted by a breaking wave on the seaward face of a vertical breakwater is plotted in Figure 2, showing a sharp pulse superimposed to a slowly varying, pulsating load. In order to perform numerical simulation of the dynamic response of caisson breakwater to wave loading, a parameterised time-history load needs to be assumed for use in the computations. An example idealised load-history is superimposed on an original signal in Figure 2; the triangular spike is characterized by the maximum reached by the signal during loading $\left(P_{\max }\right)$ and the time $\left(t_{r}\right)$ taken to get to $P_{\max }$ from 0 . The shaded area in Figure 2 represents momentum transfer to the structure during the impact: the impulse. 
Several simplified models exist in literature for time-history load for use in dynamic analysis of caisson breakwater subject to impulsive and quasi-static wave loading (see Cuomo, 2005 for a review), selected models are summarised in Table 2 .

Parameter $F_{q s^{+}}$in Table 2 stands for the quasi-static seaward force as predicted by Goda's method in its original formulation (Goda, 1974) while impact maximum $\left(F_{\max }\right)$, rise time $\left(t_{r}\right)$ and duration time $\left(t_{d}\right.$, Figure 2$)$ need to be evaluated according to guidance given in the referred documents. Model by Shimosako and Takahashi (1999) is the most to sophisticated up to date, and has been widely adopted in Japan as a basis for the evaluation of sliding of caisson breakwaters. Based on observations from small scale laboratory experiments, Kim et al. (2004) suggested reducing the amplitude of the quasi-static component of about $20 \%$ when assessing the permanent displacement due to sliding and tilting of caisson breakwaters subject to wave impacts. Among the models summarised in Table 2, the "church-roof" proposed by Oumeraci and Kortenhaus (1994) and the model by Shimosako et al (1994) (and successive modifications by Shimosako and Takahashi, 1999, Kim and Takayama, 2003 and Kim et al. 2004) have been found to give the most detailed representation of the variation in time of the overall loading. In this work we used the model originally proposed by Shimosako et al. (1994) as it includes both impulsive and pulsating (positive landward and negative - seaward) force.

Observing Tables 1 and 2, it is evident that since the early 60's, models for caisson dynamics have continuously improved side by side with the gain in knowledge on wave loading and their effects on caisson breakwaters. Although representing most of the main features of caisson dynamics, existing models do not nevertheless allow to represent the effect of the variation in time of the loading on the coupling between the dynamic response of the structure and the bearing capacity of the soil. While the full-dynamic FEM presented in Takahashi et al. 1994 is the only to make an exception, it is not yet suitable for use in performance design of caisson breakwaters, for which a large number of simulations is needed. Bearing this in mind, in the following a non-linear model is proposed that allows accounting for wave-structure-soil interaction but is fast and accurate enough to be used in performance design of caisson breakwater based on acceptable sliding distance in the design life time (Lupoi et al. 2007).

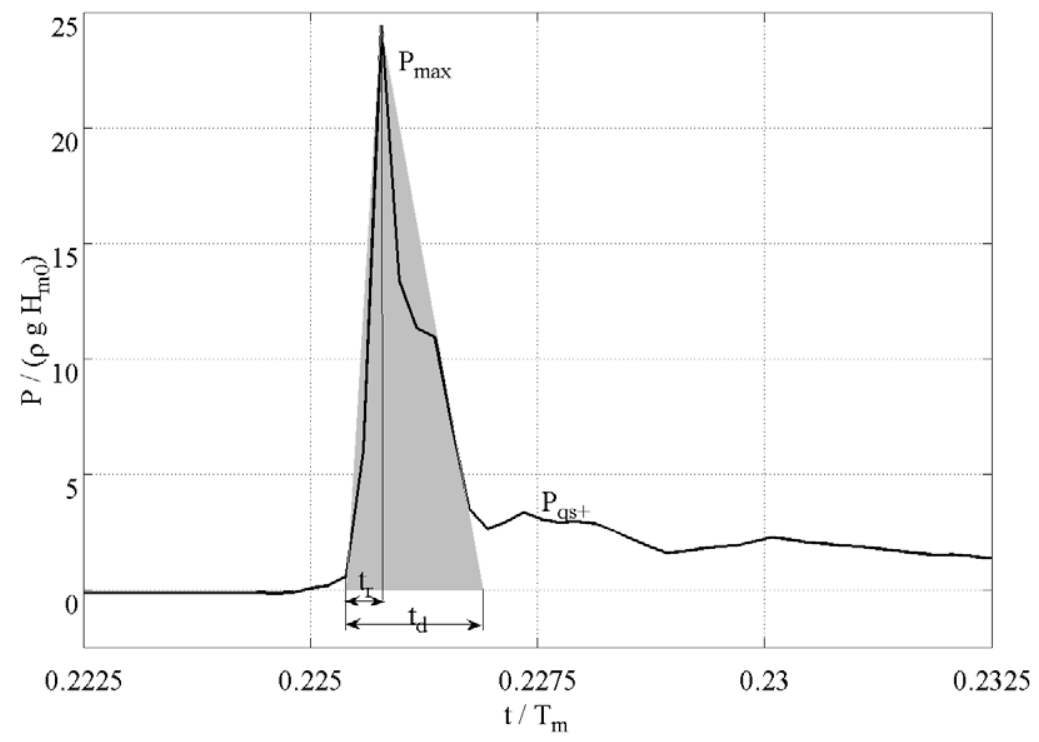

Figure 2 Example pressure time-history recorded on the seaward face of a seawall during large scale physical model tests at CIEM under VOWS research project (Cuomo et al. 2007). 
Table 2 Summary of existing wave time-history loads for use in the dynamic analysis of caisson breakwaters

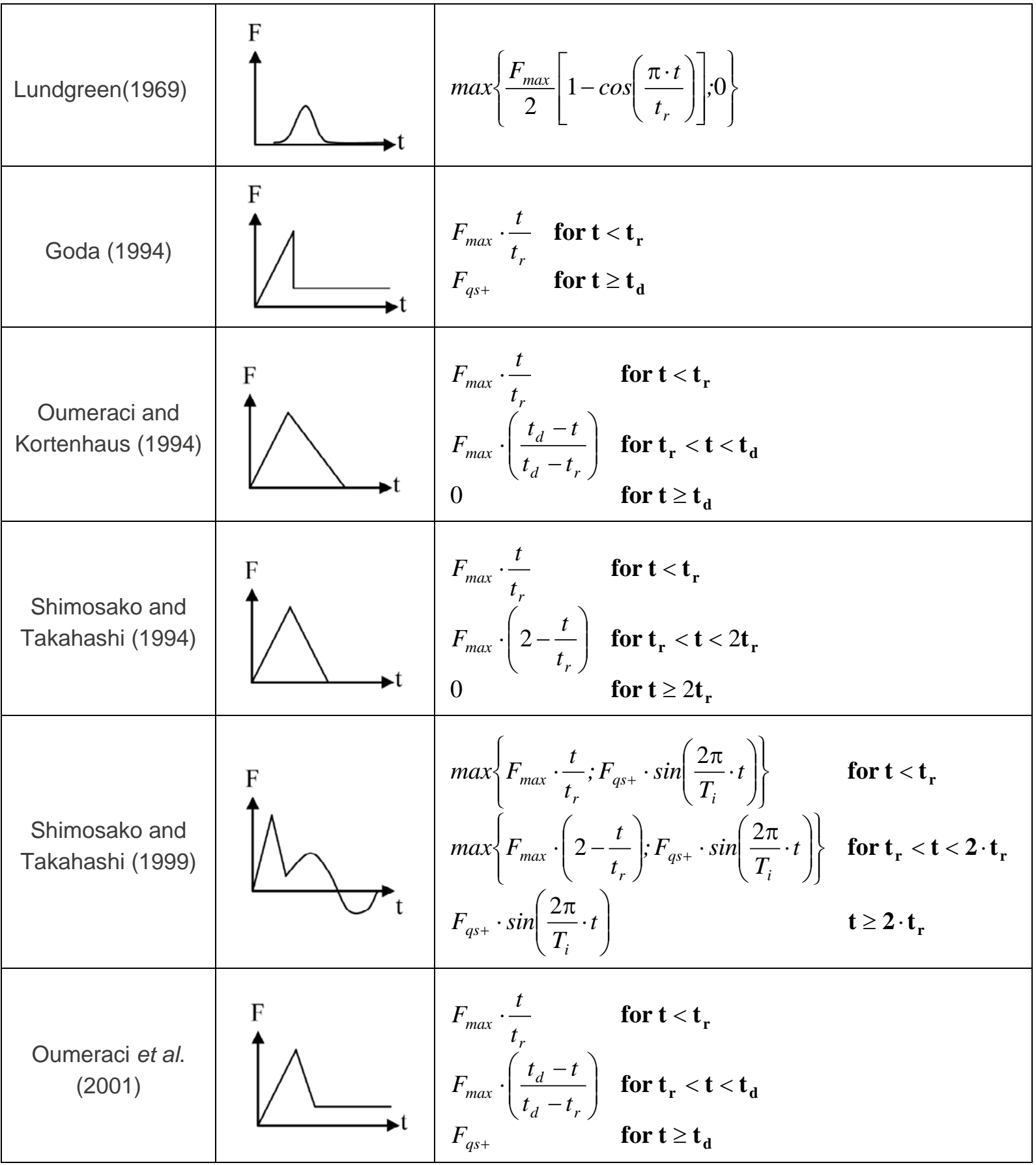




\section{A non-linear model for the dynamics of caisson breakwater}

\subsection{Dynamics of caisson breakwater subject to wave loading}

In the following, a non-linear model is introduced that allows to evaluate the sliding of caisson breakwater subject to both pulsating and impulsive wave loads. The mathematical idealisation of the problem is shown in Figure 3, where the caisson is represented by a rigid block sitting on a mattress of non-linear springs. When a wave hits the superstructure, the caisson transmits a combination of (horizontal and vertical) forces to the foundation soil. The resistance to horizontal and vertical loads are respectively represented by the Coulomb's frictional force developed at caisson-soil interface and by the bearing reaction of the soil.

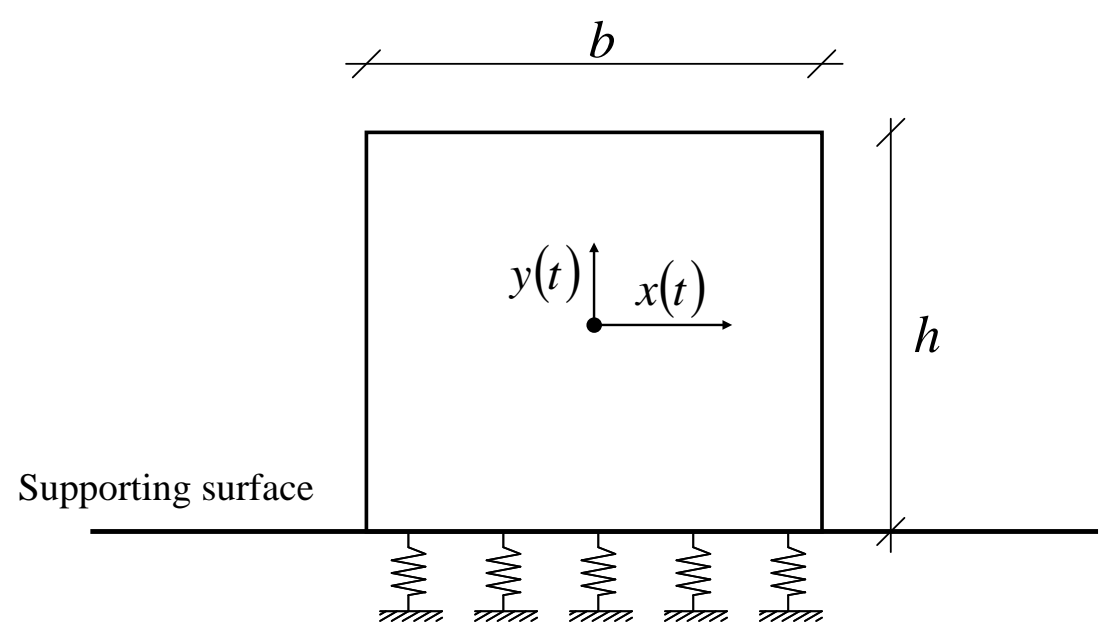

Figure $3 \quad$ Mathematical idealisation of a caisson breakwater adopted in the present model, the springs at the interface between the superstructure and its soil foundation represent non-linear elements described in $\S 3.1$ and 3.2

For a static system, the conditions for at rest are expressed by:

$$
\begin{aligned}
& \left|F_{x}(t)\right| \leq \mu_{s} \cdot\left[\left(m_{c}-m_{w}\right) \cdot g-F_{y}(t)\right] \\
& {\left[\left(m_{c}-m_{w}\right) \cdot g-F_{y}(t)\right] \geq 0} \\
& \left|F_{x}(t)\right| \leq \frac{1}{y_{L}} \cdot\left[-F_{y}(t) \cdot x_{L}+\left(m_{c}-m_{w}\right) \cdot g \cdot x_{g}\right]
\end{aligned}
$$

where $\mu_{s}$ is the static friction coefficient between the caisson structure and the foundation soil, $m_{c}$ is the mass of the caisson structure, $m_{w}$ is the mass of the volume of water displaced by the caisson, $x_{L}$ and $y_{L}$ are respectively the lever arms of vertical and horizontal wave-induced forces, $x_{g}$ is the level arm of the gravitational load.

Equations 9 and 10 describe the equilibrium in the horizontal and vertical direction, respectively, while equation 11 represents the moment equilibrium around the corners. The onset of the movement of the body is determined when one of the previous equations is no longer valid originating, respectively, sliding (Eq. 9), uplift (Eq. 10) and rocking (Eq. 11) motion. 
The equation of motion can be written according to the more general formulation (valid for both the static and dynamic system) as:

$$
\mathbf{M} \cdot \ddot{\mathbf{u}}(t)+\mathbf{C} \cdot \dot{\mathbf{u}}(t)+\mathbf{K} \cdot \mathbf{u}(t)=\mathbf{F}(t)
$$

where a dot denotes differentiation with respect to time, $\mathbf{M}, \mathbf{C}$ and $\mathbf{K}$ are, respectively, the mass, the damping and the stiffness matrixes at the free degrees of freedom. In the simplified formulation adopted in this paper, the vector $\mathbf{u}$ is composed by the displacement along $\mathbf{x}$, the displacement along $\mathrm{y}$ and the rotation, $\theta$. The vertical and the horizontal displacement at each spring, $u_{x i} u_{x, i}$ and $u_{y, i}$, are related to the three degrees of freedom $\left(u_{x}, u_{y}, u_{\theta}\right)$ by the following equations:

$$
\begin{aligned}
& u_{x, i}=u_{x} \\
& u_{y, i}=u_{y}+u_{\theta} \cdot x_{i},
\end{aligned}
$$

where $x_{i}$ is the position of the spring with respect of the centroid of the rigid block.

The resisting forces at the three degrees of freedom are then evaluated as a function of reaction at each spring, by means of the following set of equations:

$$
\begin{aligned}
& F_{x}(t)=m_{x} \cdot \ddot{u}_{x}(t)+c \cdot \dot{u}_{x}(t)+\left[\sum_{i=1}^{n_{\text {spring }}} k_{x, i}\right] \cdot u_{x}(t) \\
& F_{y}(t)=m_{y} \cdot \ddot{u}_{y}(t)-m_{w} \cdot g+c_{y} \cdot \dot{u}_{y}(t)+\left[\sum_{i=1}^{n_{\text {spring }}} k_{y, i} \cdot\left(u_{y}(t)+u_{\theta}(t) \cdot x_{i}\right)\right] \\
& F_{\theta}(t)=m_{\theta} \cdot \ddot{u}_{\theta}(t)+c_{\theta} \cdot \dot{u}_{\theta}(t)+\left[\sum_{i=1}^{n_{\text {spring }}} k_{y, i} \cdot x_{i} \cdot\left(u_{y}(t)+u_{\theta}(t)\right)\right]
\end{aligned}
$$

In the numerical solution of differential equations (Eq.12) the acceleration, velocity ad displacement a time $t+\Delta t$ are expressed in term of acceleration, velocity and displacement at time $t$. The evolution equations are here solved by means of Newmark's method (Newmark, 1959), while the Newtown-Raphson algorithm scheme (Chopra, 2001; Chapter 15) has been adopted to solve for the non-linearity of the system (§ 3.2). Precisely, at each time step, we first evaluate the unknown acceleration, velocity and displacement at time $t+\Delta t$, then we check the equilibrium between the applied forces and the resisting ones and iterate until convergence is achieved.

The dynamic properties (mass, stiffness and damping) of the system that are represented in the model include contributions by the superstructure, the water surrounding the structure and the soil foundation. In the present formulation, the two contributions are evaluated according to Equations 2 - 4 (Oumeraci and Kortenhaus, 1994), where the transitional and rotational hydrodynamic masses are given respectively by (Pedersen, 1997):

$$
\begin{aligned}
& m_{\text {hyd }, x}=0.543 \cdot \rho_{w} \cdot d^{2} \\
& m_{h y d, \theta}=0.218 \cdot \rho_{w} \cdot d^{2}
\end{aligned}
$$

where $\rho_{w}$ is the water density and $d$ the water depth in front of the wall. A more sophisticated model is employed for the description of the dynamics properties of the soil foundation, whose linear (§ 3.1) and nonlinear (§ 3.2) aspects are described in details in the following. 


\subsection{Dynamic properties of soil foundation, linear aspects}

For massless strip foundation resting on the surface of an elastic undamped homogeneous half plane Wolf (1988, Chapter 2) derived the following expressions for the vertical $\left(K_{y}\right)$ and horizontal $\left(K_{x}\right)$ stiffness (per unit length):

$$
\begin{aligned}
& K_{y}=\left(1+4 v^{2}\right) \cdot G \\
& K_{x}=\left(1+5 v^{2}\right) \cdot G
\end{aligned}
$$

where $v=0.33$ is the Poisson's ratio and $G$ is the shear modulus.

For the damping term $(C)$ the classical expression by Lysmer and Richart (1966) has been adopted:

$$
C=\frac{3.4}{1-v} \cdot r_{0}^{2} \cdot \sqrt{G \rho_{s}}
$$

in which $\rho_{s}$ is the mass density of the soil and the characteristic dimension of the equivalent circular footing has been taken as $r_{0}=\sqrt{b l / \pi}, b$ and $l$ being the planar dimensions of the caisson.

The shear modulus $G$ in Equations 20, 21 and 22 above is given by $G=E /[2(1+v)]$ in which Young's modulus $E$ of the foundation soil underneath the caisson (that is at an effective vertical stress $\sigma_{v}$ ) has been taken as (Lunne et al., 1997):

$$
E=E_{100} \sqrt{\frac{\sigma_{v 0}^{\prime}+\Delta \sigma_{v}^{\prime} / 2}{\sigma_{v 0}^{\prime}}}
$$

in which $E_{100}$ is the Young's modulus of the soil foundation corresponding to an effective strain $\sigma_{v}^{\prime}=\sigma_{v 0}^{\prime}=$ $100 \mathrm{kPa}$ and $\Delta \sigma_{v}^{\prime}=\sigma_{v}^{\prime}-\sigma_{v 0}^{\prime}$ is the additional effective strain with respect to $\sigma_{v 0}^{\prime}$. When no direct measurements are available at the site, values of $E_{100}$ can be taken from those listed in literature (see, among others: Gazetas, 1991 and Oumeraci et al. 2001 and references therein). In our computations we assumed $E_{100}=350 \mathrm{MPa}$, that is our soil foundation to consist of medium dense sand.

In the linear case, the mass, damping and stiffness matrixes for the equation of motion presented in Eq.12 are given by:

$$
\begin{aligned}
\mathbf{M} & =\left[\begin{array}{ccc}
m_{x} & 0 & 0 \\
0 & m_{y} & 0 \\
0 & 0 & m_{\theta}
\end{array}\right]=\left[\begin{array}{ccc}
m_{c}+m_{h y d, x} & 0 & 0 \\
0 & m_{c} & 0 \\
0 & 0 & m_{c}+m_{h y d, \theta}
\end{array}\right] \\
\mathbf{C} & =\left[\begin{array}{ccc}
C & 0 & 0 \\
0 & 10 \cdot C & 0 \\
0 & 0 & 10 \cdot C
\end{array}\right]
\end{aligned}
$$




$$
\mathbf{K}=\left[\begin{array}{ccc}
K_{x} & 0 & 0 \\
0 & K_{y} & K_{y \theta} \\
0 & K_{y \theta} & K_{\theta}
\end{array}\right]=\left[\begin{array}{ccc}
n_{\text {spring }} \cdot k_{x, i} & 0 & 0 \\
0 & n_{\text {spring }} \cdot k_{y, i} & -\sum_{i=1}^{n_{\text {spring }}} k_{y, i} \cdot x_{i} \\
0 & -\sum_{i=1}^{n_{\text {spring }}} k_{y, i} \cdot x_{i} & \sum_{i=1}^{n_{\text {spring }}} k_{y, i} \cdot x_{i}^{2}
\end{array}\right]
$$

Although in a relatively simplified fashion, Equations 20,21 and 22 effectively characterise the linear behaviour of the soil foundation of the breakwater while the superstructure sits on the rubble mound. Nevertheless, during most violent impacts, wave induced horizontal (shoreward) and vertical (uplift) loads may indeed concur to partially up-lift the caisson from its original position so that only part of the foundation participates to resist sliding. In such cases, Equations 9-14 do not provide anymore a realistic description of the dynamics of the system since they require tensile capacity to be provided between the structure and the soil. In the following, an improved model is introduced that allows accounting for partial lifting of the caisson from its soil foundation.

\subsection{Non-linear aspects}

In the present model, the soil foundation has been modelled by means of non-linear finite elements (springs) to allow accounting for the following non-linear features of foundation soil:

- the inability of carrying axial tension;

- the dependency of the friction between the caisson and the foundation soil on the effective strain at the interface.

Bearing this in mind, the vertical and horizontal response of each spring has been coupled, resulting in the following expressions for the stiffness, respectively in the vertical and the horizontal direction:

$$
\begin{aligned}
& k_{y, i}(t)= \begin{cases}k_{y, i} & \text { for } u_{y, i}(t) \leq 0 \\
0 & \text { otherwise }\end{cases} \\
& k_{x, i}=\left\{\begin{array}{lll}
\overline{k_{x, i}} \cdot \frac{F_{y, i}(t)}{-\overline{F_{y, i}}} & \text { for } F_{y, i}(t)<0 \text { and } & |u(t)| \leq \overline{u_{x}} \\
0 & \text { for } F_{y, i}(t)<0 \text { and } & |u(t)|>\overline{u_{x}} \\
0 & \text { for } F_{y, i}(t) \geq 0
\end{array}\right.
\end{aligned}
$$

where $k_{y, i}$ is the vertical stiffness of each spring $i$ given by $k_{y, I}=K_{y} / n_{\text {spring}} ; k_{x, i}$ is the horizontal stiffness expressed as a linear function of the vertical force $F_{y, i}(t), \overline{F_{y, i}}$ is the vertical force acting on the $i$-th spring at rest (gravitational load); $\overline{k_{x, i}}$ is the horizontal stiffness at rest given by $\overline{k_{x, i}}=K_{x} / n_{\text {spring }} ; \overline{u_{x}}$ is the displacement at incipient sliding corresponding to $\overline{u_{x}}=\mu_{s} \cdot W / K_{x}$. The resistance force due to friction is equal to $\mu_{S} \cdot F_{y, i}(t)$ at rest and to $\mu_{D} \cdot F_{y, i}(t)$ during sliding and $\mu_{s}$ and $\mu_{d}$ are respectively the static and the dynamic friction coefficients, taken respectively as 0.6 and 0.4 .

A representation of the force-displacement relationships for both the horizontal and the vertical directions is shown in Figure 4. 

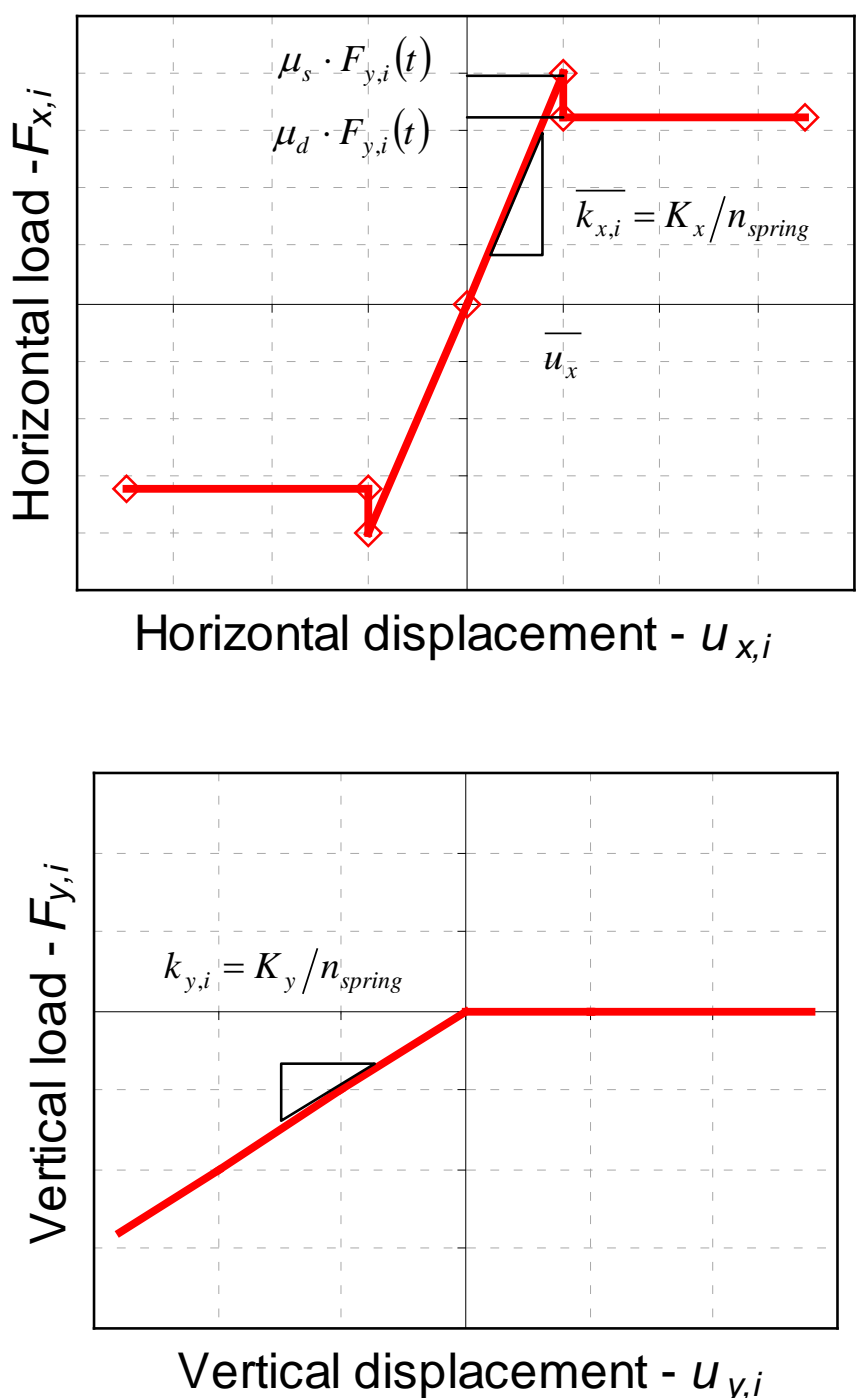

Figure $4 \quad$ Force-displacement relationship of horizontal (top) and vertical (bottom) resistance forces. The horizontal motion (top) is described by means of a friction model as a function of the vertical force: $F_{y, i}(t)$, the yield displacement: $\overline{u_{x}}$ and the static and dynamic friction coefficients: $\mu_{s}$ and $\mu_{d}$. The vertical motion (bottom) is described by means of a bilinear model, function of the vertical displacement $u_{y, i}(t)$.

\section{GENERATION OF TIME-HISTORY LOADS}

\subsection{Non-breaking wave time-history loads}

Under non-break waves attack, time-history loads are assumed to follow a slowly varying, sinusoidal path. For the $j$-th wave, the following expression is assumed for the generation of both horizontal and vertical force time history loads $F(t)$ : 


$$
F(t)=\left\{\begin{array}{cc}
\alpha_{q s} \cdot F_{q s+} \cdot \sin \left(\frac{2 \pi}{T_{j}} \cdot t\right) & \text { for } \mathbf{t}<\mathbf{T}_{\mathbf{j}} / \mathbf{2} \\
F_{q s-} \cdot \sin \left(\frac{2 \pi}{T_{j}} \cdot t\right) & \text { for } \mathbf{t} \geq \mathbf{T}_{\mathbf{j}} / \mathbf{2}
\end{array}\right.
$$

where $T_{j}$ is the wave period and $F_{q s^{+}}$and $F_{q s_{-}}$are the quasi static (in turn horizontal and vertical) positive (shoreward, uplift) and negative (seaward, suction) force corresponding to pressure distribution predicted using respectively models by Goda (2000) and Sainflou (1928). Reduction coefficient $\alpha_{q s}$ has been set equal to 0.8 according to recommendations by Kim et al. (2004), based on recent physical model tests at University of Kyoto. Level arms of overturning moments due to forces in Equation 29 are evaluated integrating pressure distribution by the corresponding theories.

\subsection{Breaking wave time-history loads}

Typical breaking wave time-history load on a vertical wall is plotted in Figure 2, showing a high magnitude short duration peak superimposed to a slowly varying pulsating load. Cuomo et al. (2010) analysed breaking wave loads on vertical walls recorded during large-scale physical model tests. The authors found that breaking wave impact pressures might well exceed those predicted by most established prediction methods and suggested a new set of formulae for both the impulsive and the pulsating components of the loading.

Accordingly, breaking wave time-history loads are evaluated as follows. First, the amplitude of the impulsive ( $F_{x, \max }$ ) horizontal components of breaking waves loads is computed as (Cuomo et al. 2010):

$$
F_{x, \max }=\alpha_{\text {max }} \cdot \rho_{w} g \cdot H \cdot L\left(d_{s}\right) \cdot\left(1-\frac{\left|d_{b}-d\right|}{d}\right)
$$

Where $d_{s}$ and $L\left(d_{s}\right)$ are the water depth at the toe of the breakwater and the corresponding wave length related to $T=T_{m}, d$ is the water depth in front of the caisson wall, $d_{b}$ is the water depth at breaking. Note that since Equation 30 was derived to predict random wave impact force at 1/250 significant level using wave height, $H=H_{s}$ (and assuming $H_{1 / 250}=1.8 H_{s}$ where $H_{s}$ is the significant wave height) a reduction factor $\alpha_{\max } \square=1 / 1.8$ needs to be applied to be consistent with the physics when using Equation 30 with monochromatic waves of height $H$.

The positive pulsating component $\left(F_{q^{+}}\right)$of the load is again evaluated using formulation by Goda (1974), which has been found to give the best representation of shoreward pulsating wave loads also under breaking wave attack (Cuomo et al. 2010). The negative pulsating component $\left(F_{q s-}\right)$ is evaluated according to Sainflou (1928).

The resulting force time-history for the $j$-th breaking wave load is evaluated as: 


$$
F_{j}(t)= \begin{cases}\max \left\{F_{x, \max , j} \cdot \frac{t}{t_{r}} ; F_{q s+, j} \cdot \sin \left(\frac{2 \pi}{T_{j}} \cdot t\right)\right\} & \text { for } \mathbf{t}<\mathbf{t}_{\mathbf{r}} \\ \max \left\{F_{x, \max , j} \cdot\left(2-\frac{t}{t_{r}}\right) ; F_{q s+, j} \cdot \sin \left(\frac{2 \pi}{T_{j}} \cdot t\right)\right\} & \text { for } \mathbf{t}_{\mathbf{r}}<\mathbf{t}<\mathbf{2} \cdot \mathbf{t}_{\mathbf{r}} \\ F_{q s+, j} \cdot \sin \left(\frac{2 \pi}{T_{j}} \cdot t\right) & \text { for } \mathbf{2} \cdot \mathbf{t}_{\mathbf{r}}<\mathbf{t}<\mathbf{T}_{\mathbf{j}} / \mathbf{2} \\ F_{q s-, j} \cdot \sin \left(\frac{2 \pi}{T_{j}} \cdot t\right) & \text { for } \mathbf{t} \geq \mathbf{T}_{\mathbf{j}} / \mathbf{2}\end{cases}
$$

To ensure consistency between impact maxima $\left(F_{x, \max }\right)$ and rise-time $\left(t_{r}\right)$, in Equation 31 the latter is evaluated according to the procedure described in section 4.2.2.

The vertical (uplift) force is still obtained using Equation 31, but replacing $F_{q s^{+}}$and $F_{q s-}$ with their corresponding vertical components evaluated respectively according to Goda (1974) and Sainflou (1928), while the following expression (Oumeraci et al., 2001) is used to evaluate the impact uplift force $F_{y, \max }$ as a function of the horizontal impact force $F_{x, \max }$ :

$$
F_{y, \max }=0.45 \cdot \frac{F_{x, \max }}{0.4 H_{b r}+0.7(d+e)} \cdot \frac{b}{2}
$$

in which $H_{b r}$ is the breaker height (§ 4.2.1), $b$ is the caisson width, $d$ is the water depth in front of the caisson wall and $e$ the depth by which the caisson is imbedded in the mound. Equation 32 derives from simplifying the expression for uplift forces given in Oumeraci et al. (2001) assuming a zero uplift pressure at the shoreward end of the caisson. Lever arms of overturning moments due to forces in Equations 30-32 are evaluated integrating pressure distribution by the corresponding theories (Goda, 1974; Sainflou, 1928; Oumeraci et al. 2001) up the wall.

\subsubsection{Evaluation of breaker height and water depth at breaking}

Breaker height and water depth at breaking play a major role in wave loading of caisson breakwater and their correct evaluation is a key issue when assessing the stability of a caisson under breaking wave attack. To evaluate wave loads at the structure using the present model, the following information is needed: wave height at the toe of the structure $\left(H_{s, t o e}\right)$, the water depth at breaking $\left(d_{b}\right)$ and the limiting breaker height $\left(H_{b r}\right)$ in front of the structure. In the present formulation $H_{s, t o e}$ is evaluated applying the Miche (1944) criterion for breaking while $d_{b}$ and $H_{b r}$ are evaluated according to the breaking criteria described in Oumeraci et al. (2001).

\subsubsection{Consistency between impact maxima and rise time}

Due to conservation of momentum, the impulse is a finite quantity and thus most violent impact loads will necessary correspond to very short duration and vice-versa. Several attempts have been made to define a functional relation between wave impact maxima and rise times (see Cuomo (2005) for a review) including analytical formulations (based on conservation of momentum and compressibility of air-water mixture) and empirical relations, usually in the form:

$$
F_{x, \max }=a \cdot t_{r}^{b}
$$


Here, consistency between generated wave impact maxima and rise time has been insured by means of the following simplified procedure. For each wave height $H_{i}$ and period $T_{i}$, the impact force $F_{x, \max , i}$ and the quasi static force $F_{a s+i}$, are evaluated respectively according to Equation 30 and Goda (1974), together with the dimensionless impact force $F^{*}=F_{x, \max } / F_{q s+}$. The normalised impact rise time $t^{*}=t_{r} / T_{m}$ is then assumed to obey a log-normal distribution, that is:

$$
f\left(t_{r}^{*}, \mu, \sigma\right)=\frac{1}{t_{r}^{*} \cdot \sigma \cdot \sqrt{2 \pi}} \cdot \exp \left[-\frac{\left(\ln t_{r}^{*}-\mu\right)^{2}}{2 \sigma^{2}}\right]
$$

To ensure consistency between impact maxima and rise times, parameters $\sigma$ and $\mu$ in Equation 34 are taken as a function of $F^{*}$ as follows:

$$
\begin{aligned}
& \mu\left(F^{*}\right)=a_{\mu} \cdot F^{* b_{\mu}} \\
& \sigma\left(F^{*}\right)=a_{\sigma} \cdot F^{* b_{\sigma}}
\end{aligned}
$$

where the empirical parameters $a_{\mu}=0.34, b_{\mu}=-3.42$ and $a_{\sigma}=0.87, b_{\sigma}=-0.26$ have been fit to data gathered during physical model tests described in Cuomo et al. (2010). A realisation for $t_{r}$ corresponding to a given $F^{*}$ is hence randomly generated according to Equation 34 with parameters $\sigma$ and $\mu$ given in Equations 35 and 36 as a function of $F^{*}$.

Figure 5 shows the comparison of example generated (circles) dimensionless impact maxima $\left(F_{\max } / F_{q s^{+}}\right)$ and rise time $\left(t_{r} / T_{m}\right)$, with prediction using Equation 34 at 50\% (black dots) and 95\% (grey dots) nonexceedance probability levels. It might be noticed that consistency between wave impact maxima and rise times is only partially insured by the procedure described above as variability in $t_{r}^{*}$ is only partially coupled with impact maxima by means of existing functional relationship between parameters $\sigma$ and $\mu$ in Equations 35 and 36 and values of $F^{*}$. A deeper coupling between variability in $t_{r}^{*}$ and $F^{*}$ might have been obtained by considering the joint probability of impact maxima and rise-time as suggested in Cuomo et al. (2009), based on joint probability distribution of impact maxima and rise times. Although less rigorous than the latter, the former formulation has been found to give an efficient and intuitive representation of the effective variability in impact maxima and rise times and is therefore been employed in the present calculations. 


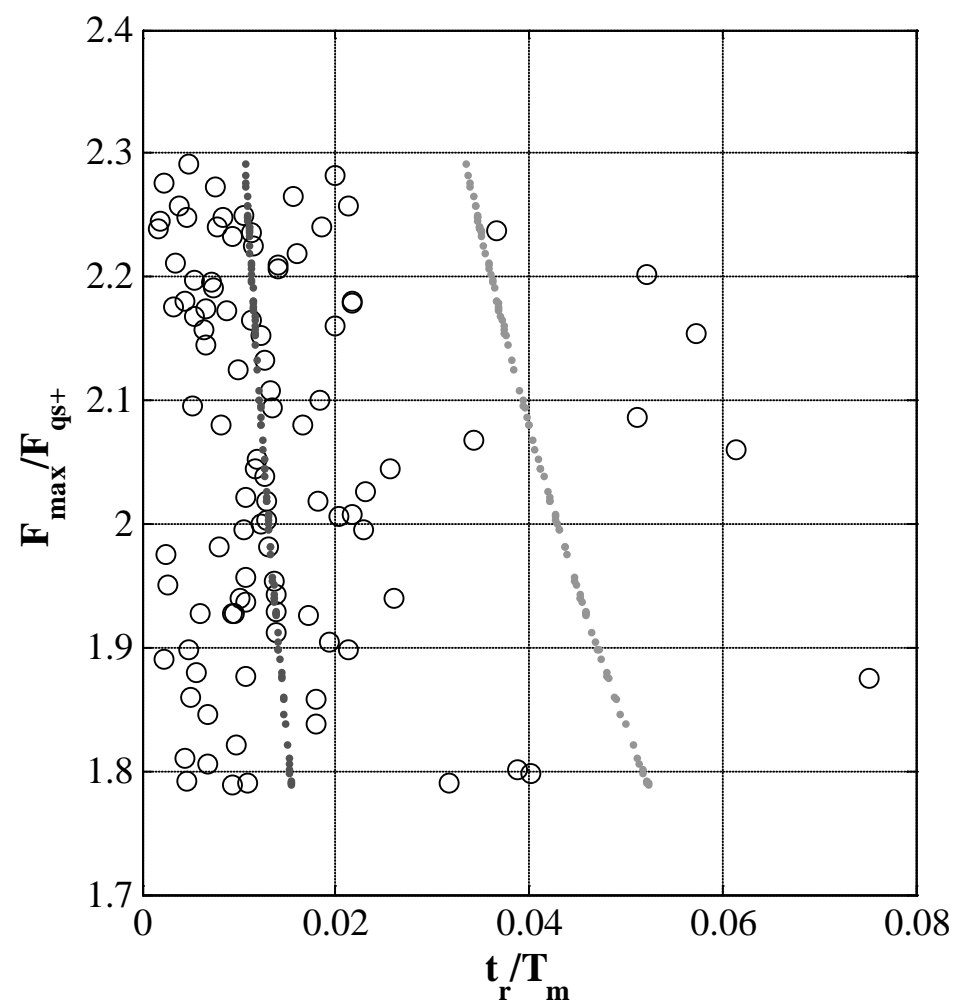

Figure $5 \quad$ Example impact maxima and rise times (circle) randomly generated according to procedure in $\S 4.2$ using monochromatic waves $\mathrm{H}=0.45 \mathrm{~m}, \mathrm{~T}=3 \mathrm{~s}, \mathrm{~d}=0.4 \mathrm{~m}$.

\section{Verification of the dynamic model and illustrative example calculations}

\subsection{Quasi-static application of a horizontal force exceeding the static friction resistance $\left(F_{x}>\mu_{s} F_{y}\right)$}

We applied a static horizontal (shoreward) force on the seaward face of the caisson at the still water level (s.w.l.) thus generating a clockwise overturning moment that tends to overturn the caisson shorewards.

Results are shown in Figure 6, in terms of (from top to bottom) horizontal reaction, horizontal displacement, vertical reaction and displacement at each of the four springs used to model the soil foundation. From left to right graphs refer to springs along the caisson base from the seaward to the shoreward face.

The effect of the overturning moment is evident in the bottom panels, showing vertical reactions linearly increasing moving from the shoreward towards the seaward end of the caisson. The effect of overturning moment is also noticeable in the top panels, with horizontal reactions increasing from left to right, accordingly to the fact that spring stiffness increases with increasing vertical load. 

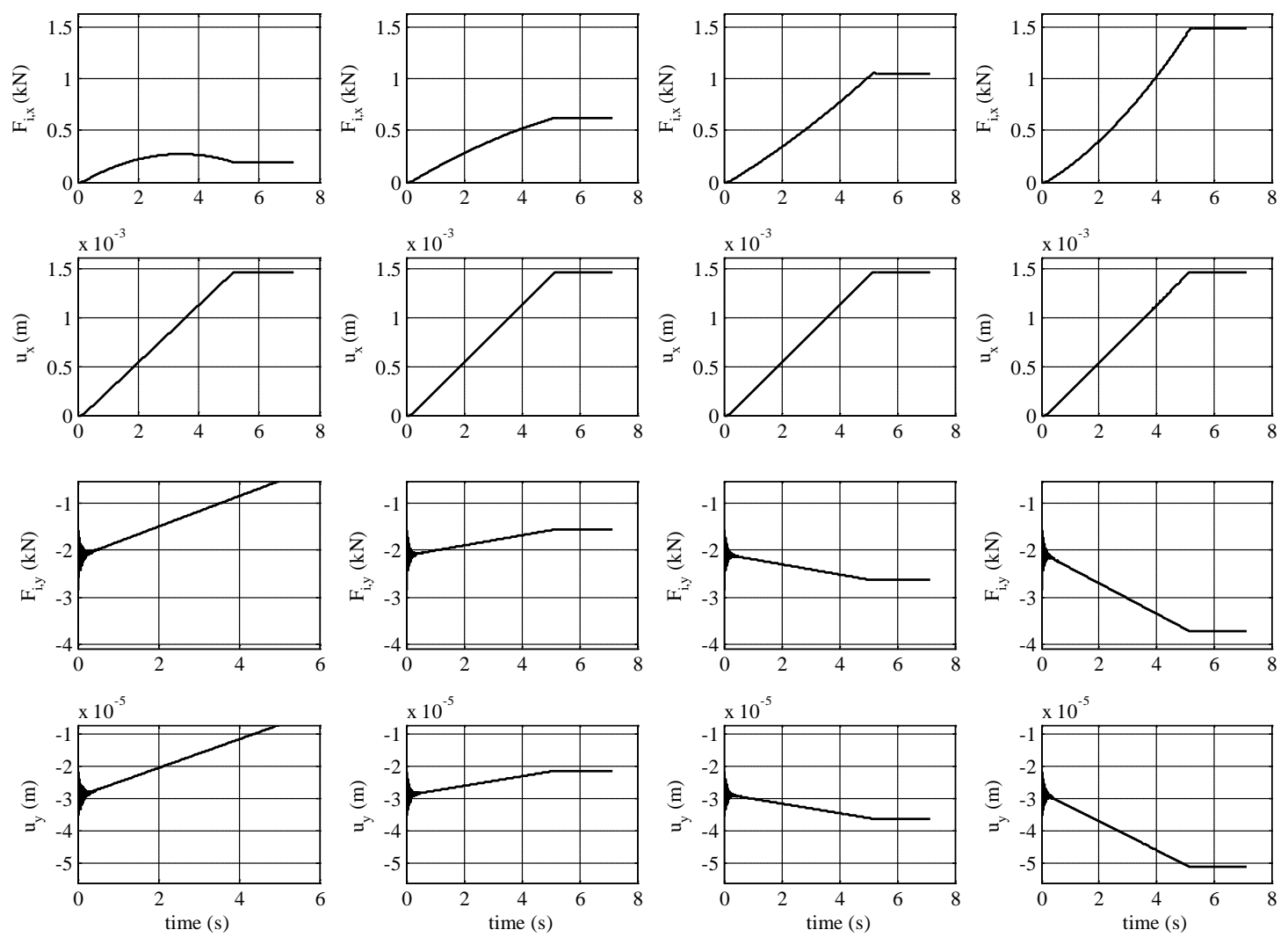

Figure $6 \quad$ Response to statically applied horizontal force (applied shoreward at s.w.I.) at locations of the four spring elements located along the caisson-soil foundation interface. From top to bottom: horizontal reaction, horizontal deformation, vertical reaction and vertical deformation. Geometrical and dynamic characteristics for this example case as follows: $l=1.0 \mathrm{~m}, b=0.78 \mathrm{~m}, h=1.12 \mathrm{~m}, d=0.40 \mathrm{~m}, K_{y}=2.9 \mathrm{E}+07$ $\mathrm{kN} / \mathrm{m} ; K_{x}=2.3 \mathrm{E}+05 \mathrm{kN} / \mathrm{m} ; \mathrm{D}=1.7 \mathrm{E}+02 \mathrm{kNs} / \mathrm{m}, \mathrm{W}=8.24 \mathrm{kN}$.

\subsection{Shock spectra of a SDOF system $\left(F_{x}<<\mu_{s} F_{y}\right)$}

The model has been applied to derive the "response spectrum" for a single degree of freedom system subject to pulse excitation, that is its "shock spectrum". The time-history load describing the pulse shape is defined by the following triangular path:

$$
F_{x}\left(t_{r}, t\right)=F_{x, \max } \cdot\left\{\begin{array}{cc}
\frac{t}{t_{r}} & t \leq t_{r} \\
2-\frac{t}{t_{r}} & t_{r}<t \leq 2 t_{r} \\
0 & t>2 t_{r}
\end{array}\right.
$$

For different values of $t_{r}$, Equation 37 describes a symmetrical triangular path having magnitude $F_{x, \max }$ and duration $2 t_{r}$. Results are presented in the range $0<t_{r} / T_{0}<5\left(T_{0}\right.$ being the natural period of vibration of the SDOF) on the left hand side of Figure 7 in terms of the amplification factor defined as:

$$
\Psi=\frac{\max \left\{u_{x}(t)\right\}}{\overline{u_{x}}}
$$


where $u_{x}(t)$ is the horizontal displacement and $\bar{u}_{x}$ is the static horizontal displacement defined as the ratio of the load intensity to the stiffness of the system $\overline{u_{x}}=F_{x} / K_{x}$.

Numerical results (circles) are almost superimposed to the analytical solution (dashed line) on the left hand side of Figure 7, demonstrating the efficiency of the model.

Effect of sliding on the dynamic response of caisson breakwater is highlighted on the right hand side of Figure 7, showing the modification of the shock spectra of the same caisson breakwater subject to an horizontal impulse having intensity comparable to the static sliding resistance of the caisson. A few conclusions can be derived by observing plots on the right hand side of Figure 7:

- for $t_{r} \ll<T_{0}$ the dynamic response of the structure reduces the force effectively felt by the caisson so that no-sliding occurs even for $F_{x, \max }>\mu_{s} \cdot W$ (static sliding resistance, SSR);

- for $t_{r} \cong T_{0}$ the dynamic response of the structure amplifies the force effectively felt by the caisson so that sliding occurs even for $F_{x, \max }<\mu_{s} \cdot W$.
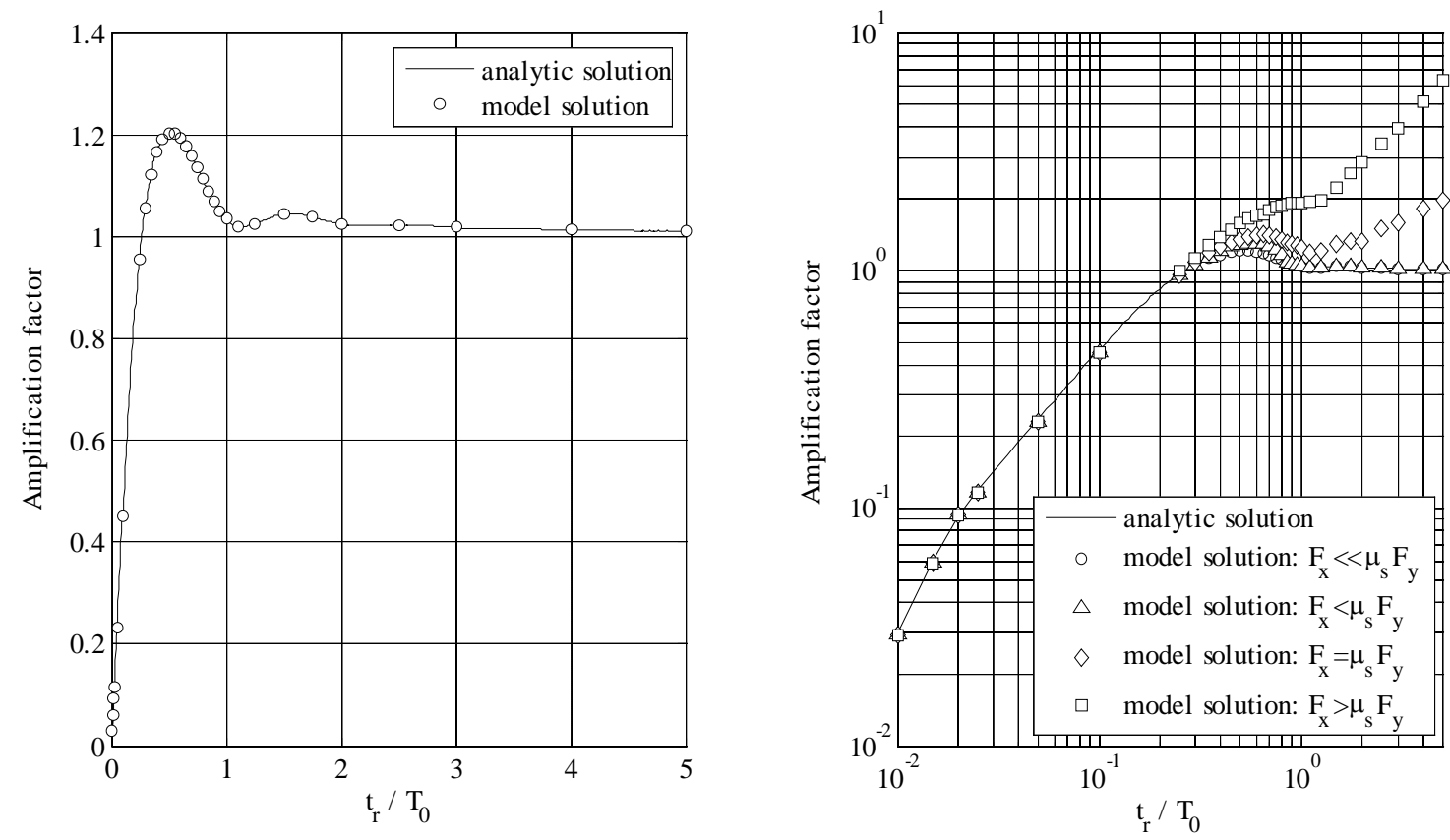

Figure $7 \quad$ Shock spectrum for caisson breakwater subject to pulse excitation. Response to the application of an horizontal force having magnitude smaller (left) and larger (right) than the static sliding resistance (SSR).

When compared to predictions by the static formulation by Shimosako et al. (1999), results using the present model show that (Figure 8):

- for $t_{r} / T_{0}<<1$ the dynamic model predicts no-sliding even if $F_{x, \max }>\mu_{s} \cdot W$;

- for $t_{r} / T_{0} \cong 1$ the dynamic model predicts larger sliding than the static approach, in particular, including the dynamic response of the structure might result in sliding of the structure even for $F_{x, \max }<\mu_{s} \cdot W$, 
- for $t_{r} / T_{0} \gg>1$, sliding predicted by the dynamic model is lower than estimates by the static approach due to the reduction of effective load due to motion of the structure.
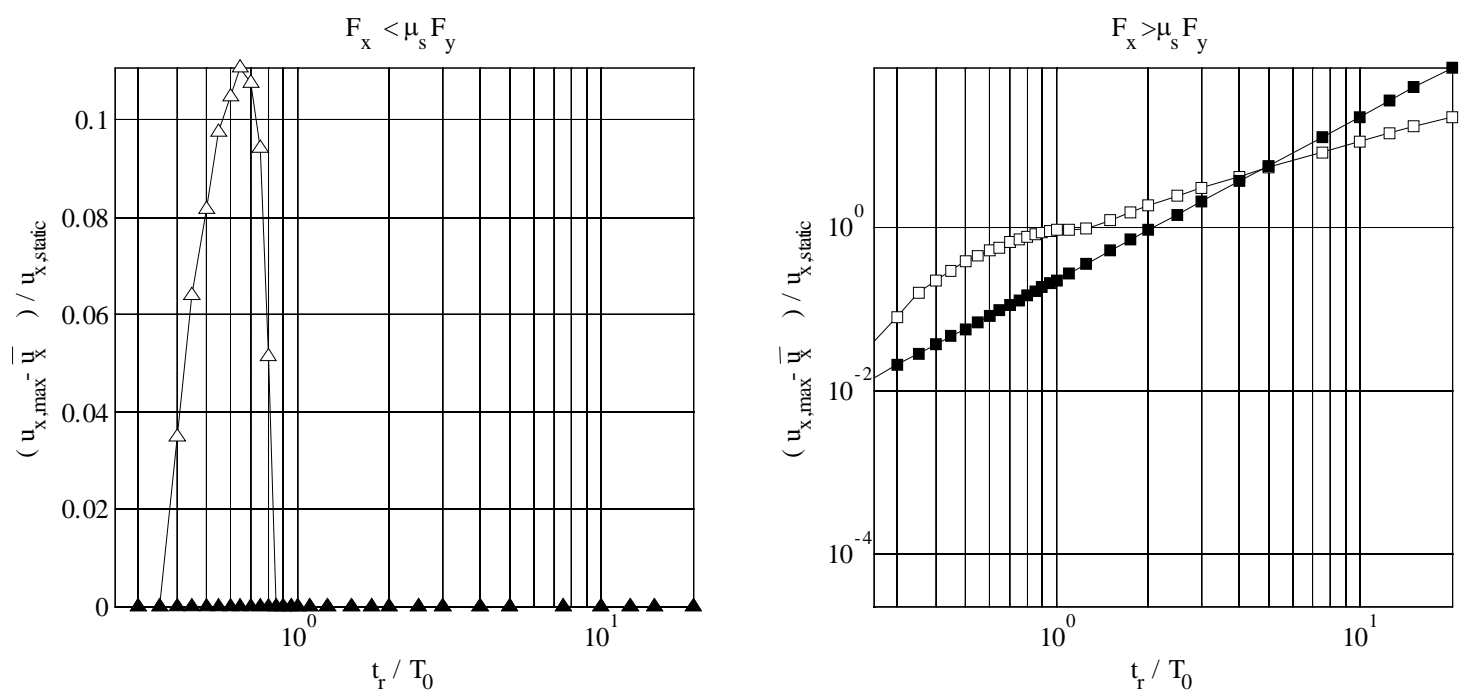

Figure $8 \quad$ Permanent displacement due to pulse excitation having maxima slightly lower (left) and higher (right) then the static sliding resistance, comparison of predictions by static approach by Shimosako et al. (1999, black marks) and the present model (white marks).

\subsection{Dynamics of caisson breakwater subject to non-breaking and breaking wave time-history loads}

Example time history loads for the case of a single non-breaking and breaking wave are represented respectively on the left hand side of Figures 9 and 10. From top to bottom, thin solid lines represent the horizontal (shoreward) and vertical (upward) forces and the overturning (clockwise) moment. Results are shown in terms of reactions (left) and deformations (right) for the caisson as a whole (solid thick line) as well as for springs at different locations along the interface between the caisson and its soil foundation (dotted line). The variation in time of the static sliding resistance (SSR) is also shown in the top left panel, highlighting instants of incipient sliding and relative motion between structure and foundation.

As the wave reaches the structure it applies a shoreward load to the caisson and the reactions of the foundation elements initially increase all over the interface. As the load increases, the caisson rotates shoreward and the seaward end of the caisson is up-lifted. At this time, both the horizontal and vertical reactions exerted by the foundation elements underneath the seaward end of the caisson start decreasing (up to zero, when the contact between the superstructure and the foundation is lost) while the elements at the shoreward end of the interface are heavily loaded. Once the water surface starts moving downwards, and a through starts appearing in front of the caisson wall, the shoreward load decreases and the caisson starts rotating seaward. When the wave trough reaches the structure, the loading process inverts until another wave reaches the structure.

If, at any time during the loading, the static sliding resistance is exceeded by the reaction that is required to the caisson for at rest, the caisson slides. At this point, the horizontal bearing capacity of the soil foundation instantaneously decreases as the incipient motion reduces the friction at the interface between the superstructure and the soil foundation, as the caisson begins to move, the velocity (dashed-dotted lines on 
the right hand side of Figures 9 and 10) rapidly increases and reaches its maximum, then decrease until the caisson suddenly stops (top right panel). As highlighted in Figure 9, the sliding of the caisson breakwater due to pulsating wave pressure develops over a significant amount of time and a single wave is able to dislocate the superstructure and to move it for a considerable distance. Sliding due to breaking wave pressure follows a completely different path, with sudden and short-lasting motion of the structure (note change of time scale between Figures 9 and 10).
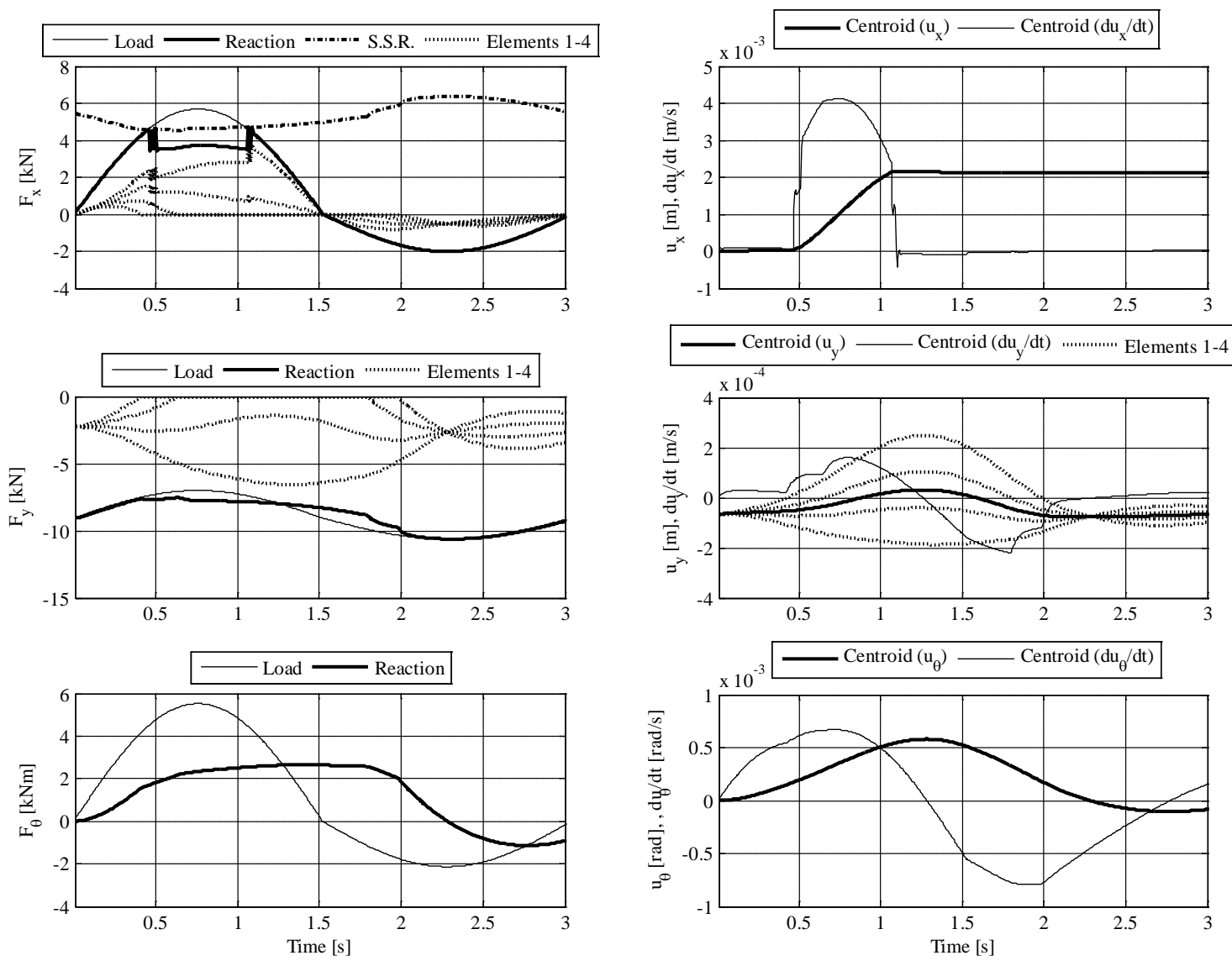

Figure $9 \quad$ Dynamic response of a caisson breakwater subject to non-breaking wave loads exceeding the static sliding resistance; note initial vertical displacement due to settling of the caisson under self-weight. Geometrical and dynamic characteristics for this example case as follows: $l=1.0 \mathrm{~m}, b=0.78 \mathrm{~m},=1.12 \mathrm{~m}, d=$ $0.80 \mathrm{~m}, K_{y}=1.4 \mathrm{E}+05 \mathrm{kN} / \mathrm{m} ; J_{x}=1.5 \mathrm{E}+05 \mathrm{kN} / \mathrm{m} ; \mathrm{D}=4.8 \mathrm{E}+02 \mathrm{kNs} / \mathrm{m}, \mathrm{W}=8.24 \mathrm{kN}$. 

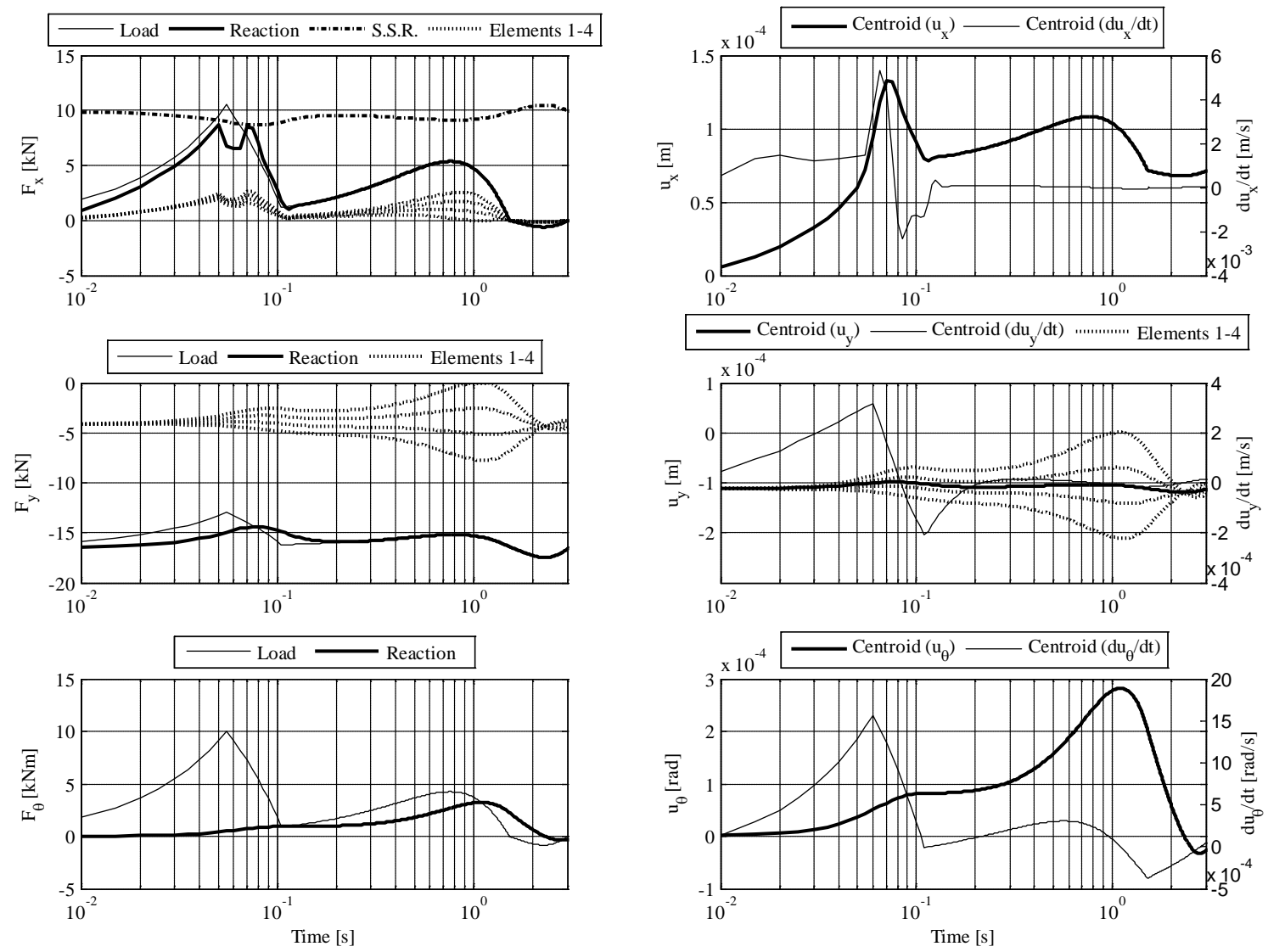

Figure $10 \quad$ Dynamic response of a caisson breakwater subject to breaking wave loads exceeding the static sliding resistance; note initial vertical displacement due to settling of the caisson under self-weight. Geometrical and dynamic characteristics for this example case as follows: $l=1.0 \mathrm{~m}, b=0.78 \mathrm{~m}, h=1.12 \mathrm{~m}, d$ $=0.40 \mathrm{~m}, K_{y}=1.5 \mathrm{E}+05 \mathrm{kN} / \mathrm{m} ; K_{x}=1.6 \mathrm{E}+05 \mathrm{kN} / \mathrm{m} ; \mathrm{D}=6.1 \mathrm{E}+02 \mathrm{kNs} / \mathrm{m}, \mathrm{W}=16.17 \mathrm{kN}$.

\section{COMPARISON WITH MEASUREMENTS FROM PHYSICAL MODEL TESTS}

\subsection{Physical model tests.}

Experiments at Port and Airport Research Institute (PARI) were performed in the $105 \mathrm{~m}$ long, $3 \mathrm{~m}$ wide and $2.5 \mathrm{~m}$ deep wave flume of the Maritime Structures Division.

A schematic representation of the experimental setup is reproduced in Figure 11. Two sets of tests were carried out respectively under pulsating and breaking wave attack. During the latter set of experiments, waves were forced to break in front of the structure by means of an extra-berm built in front of the structure (dashed line in figure) which reduced further the water depth in front of the wall (from $0.8 \mathrm{~m}$ to $0.4 \mathrm{~m}$ ).

Experiments are described in detail in Shimosako et al. (1994) and Shimosako and Takahashi (1999). Regular waves were generated in the range $0.428-0.619 \mathrm{~m}\left(H_{1,2 \ldots 4}\right.$ in, Tables 3 and 4$)$ while the wave 
period was kept constant and equal to 3.04s. Effect of caisson weight was tested in the range of 6.9-8.9 kN ( $W_{1,2, \ldots 4}$ in Table 3) for non breaking waves and 11.3-19.4 $\mathrm{kN}\left(W_{1,2, \ldots 5}\right.$ in Table 4) for breaking waves.

to scale, $1 \mathrm{~m}$

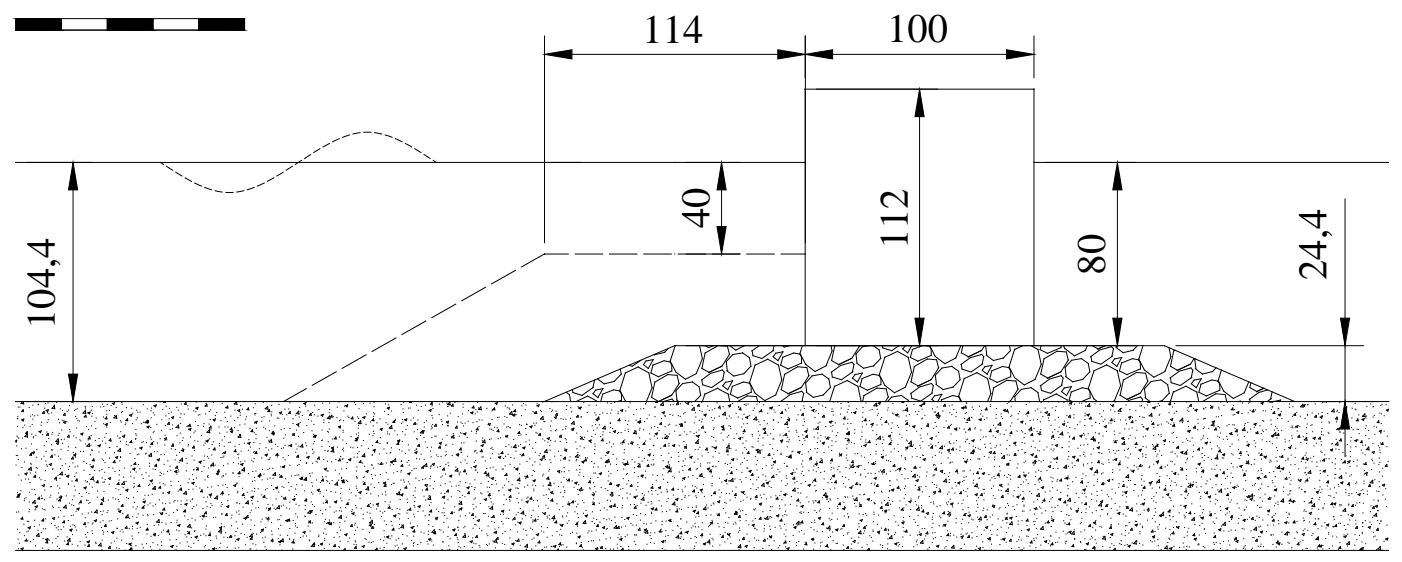

Figure 11 Experimental setup used in the small-scale physical model tests performed at PARI (units: $\mathrm{cm}$ ).

Table 3 Summary of regular wave conditions and geometrical configurations adopted for physical model tests at PARI under non-breaking wave attack.

\begin{tabular}{|c|c|c|c|c|}
\hline $\mathbf{H}$ & $\mathbf{T}$ & $\mathbf{h}_{\mathbf{s}}$ & $\mathbf{d}$ & $\mathbf{W}$ \\
$m$ & $s$ & $m$ & $m$ & $k N$ \\
\hline $\mathrm{H}_{1}=0.428$ & 3.04 & 1.14 & 0.8 & $\mathrm{~W}_{1}=7.8$ \\
$\mathrm{H}_{2}=0.524$ & 3.04 & 1.14 & 0.8 & $\mathrm{~W}_{1}=7.8$ \\
$\mathrm{H}_{3}=0.569$ & 3.04 & 1.14 & 0.8 & $\mathrm{~W}_{1}=7.8$ \\
\hline $\mathrm{H}_{1}=0.428$ & 3.04 & 1.14 & 0.8 & $\mathrm{~W}_{2}=7.5$ \\
$\mathrm{H}_{2}=0.524$ & 3.04 & 1.14 & 0.8 & $\mathrm{~W}_{2}=7.5$ \\
$\mathrm{H}_{3}=0.569$ & 3.04 & 1.14 & 0.8 & $\mathrm{~W}_{2}=7.5$ \\
$\mathrm{H}_{4}=0.619$ & 3.04 & 1.14 & 0.8 & $\mathrm{~W}_{2}=7.5$ \\
\hline $\mathrm{H}_{1}=0.428$ & 3.04 & 1.14 & 0.8 & $\mathrm{~W}_{3}=8.2$ \\
$\mathrm{H}_{2}=0.524$ & 3.04 & 1.14 & 0.8 & $\mathrm{~W}_{3}=8.2$ \\
$\mathrm{H}_{3}=0.569$ & 3.04 & 1.14 & 0.8 & $\mathrm{~W}_{3}=8.2$ \\
$\mathrm{H}_{4}=0.619$ & 3.04 & 1.14 & 0.8 & $\mathrm{~W}_{3}=8.2$ \\
\hline $\mathrm{H}_{1}=0.428$ & 3.04 & 1.14 & 0.8 & $\mathrm{~W}_{4}=8.9$ \\
$\mathrm{H}_{2}=0.524$ & 3.04 & 1.14 & 0.8 & $\mathrm{~W}_{4}=8.9$ \\
$\mathrm{H}_{3}=0.569$ & 3.04 & 1.14 & 0.8 & $\mathrm{~W}_{4}=8.9$ \\
$\mathrm{H}_{4}=0.619$ & 3.04 & 1.14 & 0.8 & $\mathrm{~W}_{4}=8.9$ \\
\hline
\end{tabular}


Table 4 Summary of regular wave conditions and geometrical configurations adopted for physical model tests at PARI under breaking wave attack.

\begin{tabular}{|c|r|r|r|c|}
\hline $\mathbf{H}$ & $\mathbf{T}$ & \multicolumn{1}{c|}{$\mathbf{h}_{\mathbf{s}}$} & $\mathbf{d}$ & $\mathbf{W}$ \\
$m$ & $s$ & $m$ & $m$ & $k N$ \\
\hline $\mathrm{H}_{2}=0.524$ & 3.04 & 1.14 & 0.4 & $\mathrm{~W}_{1}=11.3$ \\
\hline $\mathrm{H}_{1}=0.428$ & 3.04 & 1.14 & 0.4 & $\mathrm{~W}_{2}=13.7$ \\
$\mathrm{H}_{2}=0.524$ & 3.04 & 1.14 & 0.4 & $\mathrm{~W}_{2}=13.7$ \\
$\mathrm{H}_{3}=0.569$ & 3.04 & 1.14 & 0.4 & $\mathrm{~W}_{2}=13.7$ \\
$\mathrm{H}_{4}=0.619$ & 3.04 & 1.14 & 0.4 & $\mathrm{~W}_{2}=13.7$ \\
\hline $\mathrm{H}_{1}=0.428$ & 3.04 & 1.14 & 0.4 & $\mathrm{~W}_{3}=16.2$ \\
$\mathrm{H}_{2}=0.524$ & 3.04 & 1.14 & 0.4 & $\mathrm{~W}_{3}=16.2$ \\
$\mathrm{H}_{3}=0.569$ & 3.04 & 1.14 & 0.4 & $\mathrm{~W}_{3}=16.2$ \\
$\mathrm{H}_{4}=0.619$ & 3.04 & 1.14 & 0.4 & $\mathrm{~W}_{3}=16.2$ \\
\hline $\mathrm{H}_{1}=0.428$ & 3.04 & 1.14 & 0.4 & $\mathrm{~W}_{4}=17.8$ \\
$\mathrm{H}_{2}=0.524$ & 3.04 & 1.14 & 0.4 & $\mathrm{~W}_{4}=17.8$ \\
$\mathrm{H}_{3}=0.569$ & 3.04 & 1.14 & 0.4 & $\mathrm{~W}_{4}=17.8$ \\
$\mathrm{H}_{4}=0.619$ & 3.04 & 1.14 & 0.4 & $\mathrm{~W}_{4}=17.8$ \\
\hline $\mathrm{H}_{1}=0.428$ & 3.04 & 1.14 & 0.4 & $\mathrm{~W}_{5}=19.4$ \\
$\mathrm{H}_{2}=0.524$ & 3.04 & 1.14 & 0.4 & $\mathrm{~W}_{5}=19.4$ \\
\hline
\end{tabular}

Tests were carried out by taking measurements of 15 consecutive waves $\left(N_{z}=15\right)$ for a given test condition. Test conditions are summarised in Table 3 and 4 respectively for physical model tests carried out using nonbreaking and breaking wave conditions.

\section{Comparison of predictions with measurements from physical model tests at PARI.}

Numerical simulations were performed using time-history loads generated according to the procedure described in § 4-1 and 4.2. For each experiment (that is for each wave condition and geometrical configuration) 10 realizations were simulated. In this section, results from numerical simulations are compared with measurements at PARI for experiments under both non-breaking and breaking wave conditions. Although the physical model tests were performed using monochromatic waves, some variability of wave height at the toe of the structure was observed during testing. To account for this effect, waves in the numerical simulations have been assigned a random variability of about $20 \%$ of the nominal wave height.

Sliding distances measured during the experiments are compared with those predicted by the model, in terms of the mean, maximum and minimum total (over a $N_{z}=15$ waves test) sliding distance.

\section{Example calculation}

In order to facilitate application of the procedure described in this paper, an example calculation is presented in this section for one of the configurations tested during the physical model tests at PARI. Input data are summarised in Table 5.

The dynamic characteristics of the soil foundation, in terms of global horizontal and vertical stiffness and global damping can be calculated using Equations 20, 21 and 22, and are summarised in Table 6. 
Table 5 Geometrical and geotechnical characteristics of an example configuration tested during physical model tests at PARI.

\begin{tabular}{|l|l|r|l|}
\hline Caisson length (in wave direction) & $l$ & 1.00 & $\mathrm{~m}$ \\
\hline Caisson width (orthogonal to wave direction) & $b$ & 0.78 & $\mathrm{~m}$ \\
\hline Caisson weight in water & $W$ & 8.24 & $\mathrm{kN}$ \\
\hline Young's modulus at $\sigma_{\mathrm{v}}{ }^{\prime}=100 \mathrm{kPa}$ & $E_{100}$ & $3.510^{5}$ & $\mathrm{kPa}$ \\
\hline Shear modulus at $\sigma_{\mathrm{v}}{ }^{\prime}=100 \mathrm{kPa}$ & $G_{100}$ & $1.310^{5}$ & $\mathrm{kPa}$ \\
\hline Poisson's ratio & $v$ & 0.33 & - \\
\hline Soil foundation density & $\rho_{s}$ & 2300 & $\mathrm{~kg} / \mathrm{m}^{3}$ \\
\hline Water depth at the wall & $d$ & 0.80 & $\mathrm{~m}$ \\
\hline
\end{tabular}

Table 6 Dynamic characteristics of an example configurations tested during physical model tests at PARI.

\begin{tabular}{|l|l|l|l|}
\hline Caisson weight in water & $W$ & 8.24 & $\mathrm{kN}$ \\
\hline Mass & $M$ & 1464 & $\mathrm{~kg}$ \\
\hline Vertical stiffness & $K_{y}$ & $1.410^{5}$ & $\mathrm{kN} / \mathrm{m}$ \\
\hline Horizontal stiffness & $K_{x}$ & $1.510^{5}$ & $\mathrm{kN} / \mathrm{m}$ \\
\hline Damping & $C$ & $4.810^{2}$ & $\mathrm{kNs} / \mathrm{m}$ \\
\hline Natural period of vibration (undamped) & $T_{n}$ & 0.02 & $\mathrm{~s}$ \\
\hline
\end{tabular}

\section{Non-breaking wave attack.}

Time-series of wave-forces and corresponding reactions and deformations are shown in Figure 12 for a regular waves test. When sliding occurs under non-breaking waves attack, the static sliding resistance is exceeded for a significant amount of time and the resulting permanent displacement is large (§ 5.3).

Furthermore, since pulsating wave forces are less variable than impacts, a large number of waves within a single storm might induce sliding of the superstructure. This is the case when waves exceeding the wave condition assumed in the deterministic design reach the breakwater without breaking. Such condition is particularly dangerous for caissons and usually results in significant sliding of caissons units or failure of the breakwaters. Both the aforementioned effects are clearly visible in the horizontal displacement time-history shown in the top-right panel of Figure 12. 

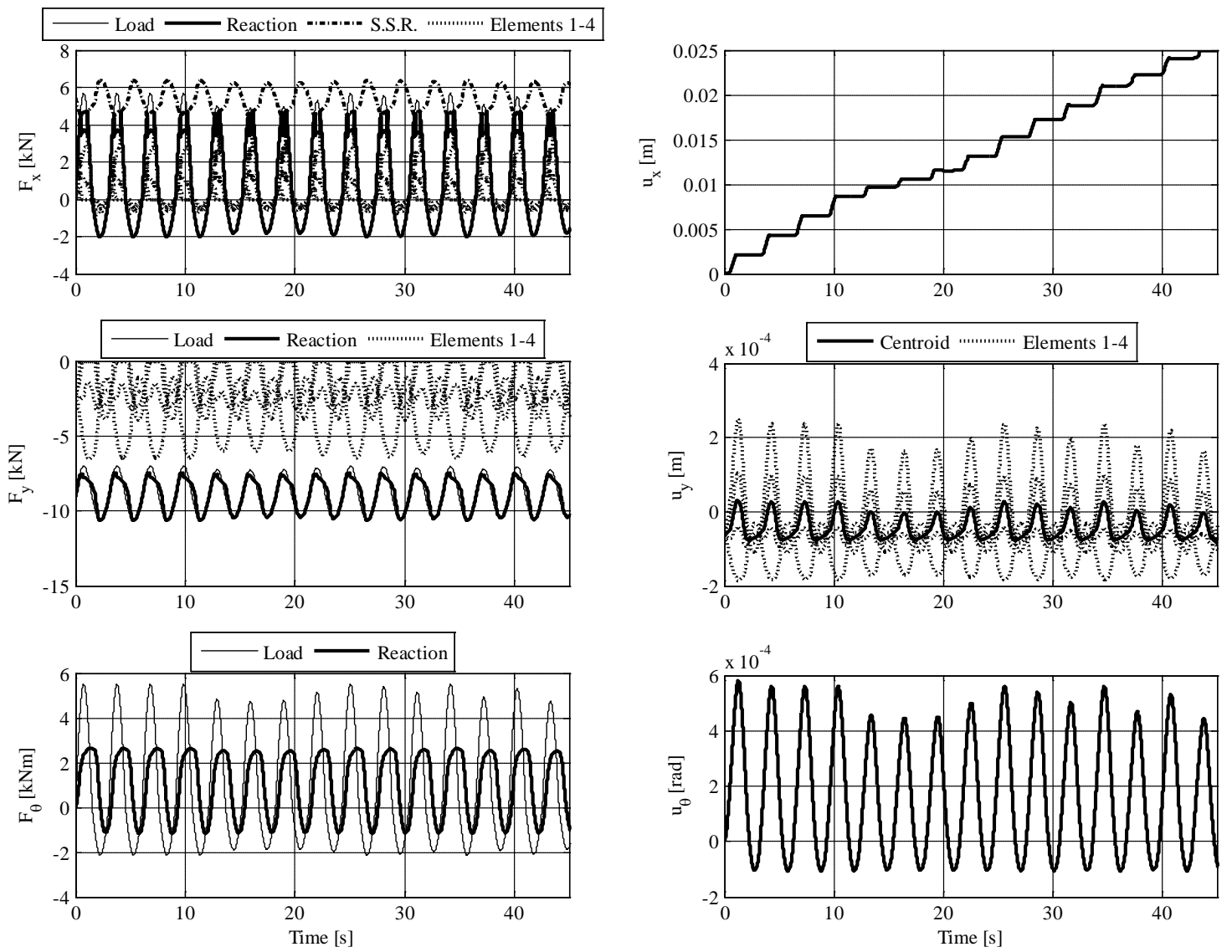

Figure12 Dynamic response of caisson breakwaters subject to non-breaking wave attack, results from a single realization using $\mathrm{N}_{\mathrm{z}}=15$ waves, geometrical and dynamic characteristics for this example case are as in Figure 9.

Results from simulations under non-breaking wave attack are summarised in Figure 13, in terms of maximum, mean and minimum total sliding distance (over 10 realizations of each $N_{z}=15$ waves test) as a function of the incident wave height and of the caisson weight. From left to right results refer to tests run with increasing caisson weight in the range $6.9 \mathrm{kN}\left(W_{1}\right)-8.9 \mathrm{kN}\left(W_{5}\right)$ and increasing wave height in the range $H=0.428 \mathrm{~m}-0.619 \mathrm{~m}$.

As expected, results from numerical simulations confirm that for a given caisson weight, the sliding distance increases for increasing wave heights while for a given wave height, the sliding decreases with increasing caisson weight. When compared to measurements from physical model tests, the model seems to give a good prediction of total sliding distances (top panel in Figure 13) when the caisson weight is relatively small $\left(W_{1}\right)$, while the model overestimates sliding when the caisson weight increases $\left(W_{2}-W_{4}\right)$. 

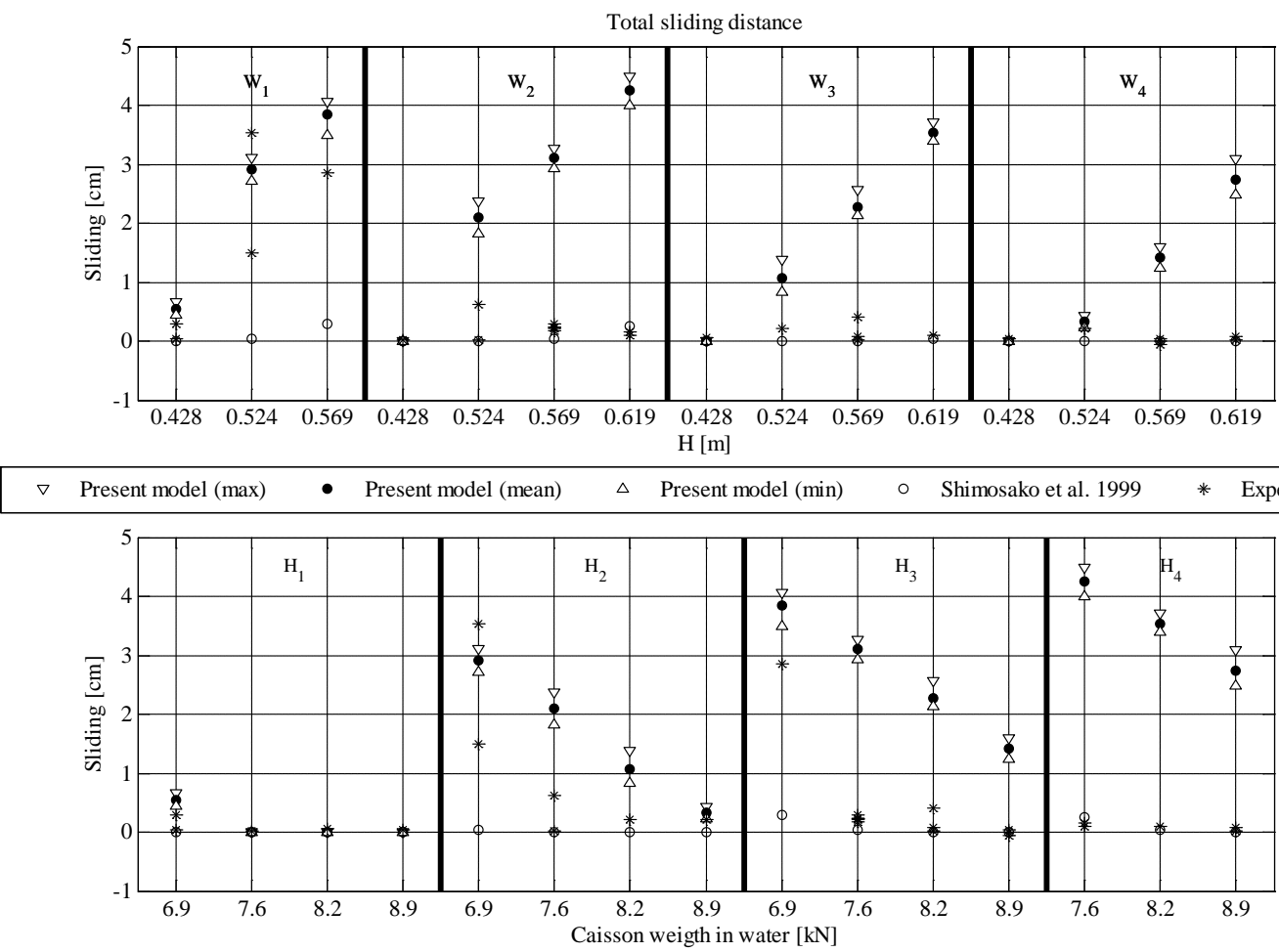

Figure 13 Sliding under non-breaking wave attack, comparison of measurements from physical model tests $\left({ }^{*}\right)$ and prediction by the present model (dots) and Shimosako et al. 1999 (circle).

When compared to predictions by Shimosako et al. (1999), both approach seem to capture the same overall trend, although predictions by the two models are significantly different, with the present model generally giving a safer estimation of total sliding distance.

\section{Breaking wave attack.}

Time-series of wave-force and corresponding reactions and deformations are shown in Figure 14 for a regular waves test.

Two major sliding events are clearly distinguishable in the otherwise slowly varying horizontal displacement time-history (top-right panel). When sliding occurs under breaking waves attack, the static sliding resistance is exceeded for a small amount of time and the resulting permanent displacement is therefore small (§ 5.3). Furthermore, since impulsive wave forces are extremely variable, during a storm only a small number of waves might be able to cause the superstructure to slide. Nevertheless, if the tidal excursion is significant (as it is in the case of the North European and Japanese coasts) heavy breaking might frequently occur at the structure, and impact magnitude might then be amplified by the dynamic response of the structure, with the effective load resulting in significant sliding of the caisson. 

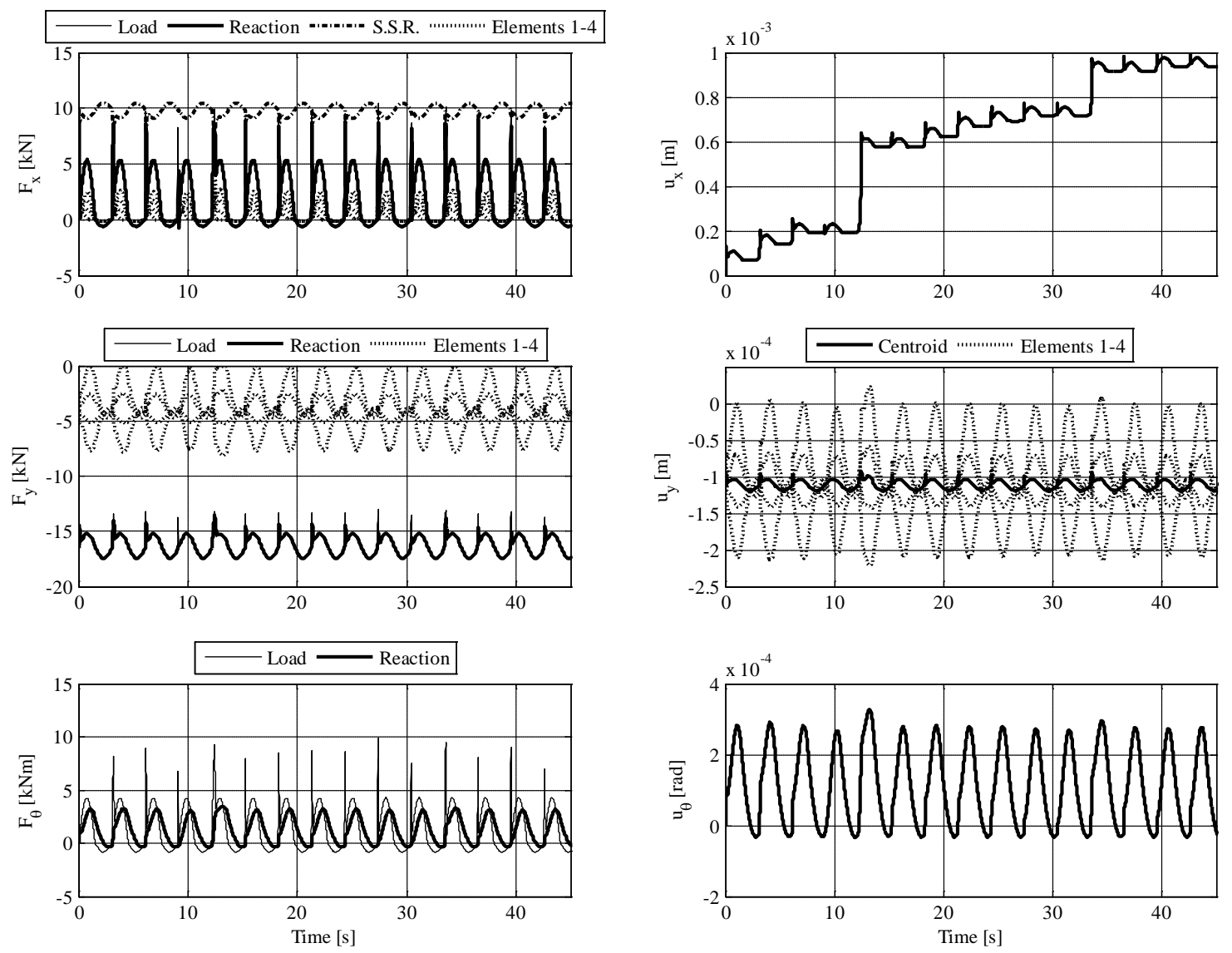

Figure $14 \quad$ Dynamic response of caisson breakwaters subject to breaking wave attack, results from a single realization using $\mathrm{N}_{\mathrm{z}}=15$ waves, geometrical and dynamic characteristics for this example case are as in Figure 10.

Results from simulations under breaking wave attack are summarised in Figure 15, in terms of maximum, mean and minimum total sliding distance (over 10 realizations of each $N_{z}=15$ waves test) as a function of the incident wave height and of the caisson weight. From left to right results refer to tests run with increasing caisson weight and increasing wave height. Not surprising, sliding decreases with increasing caisson weight, nevertheless, for a given caisson weight increasing of sliding with incoming wave height is not monotonic. This is due to non-linear effect introduced by wave breaking in both wave impact maxima (Equation 30) and rise times.

Indeed, due to the rapid variation of the water depth in front of the structure the highest waves will break before reaching the structure, resulting in relatively low maxima; on the other hand, waves reaching the wall without breaking will necessary have a lower height and thus less energy, resulting again in relatively low impact maxima. The highest impact maxima actually resulting from waves that curl just before hitting the structure but not exactly at the wall. 


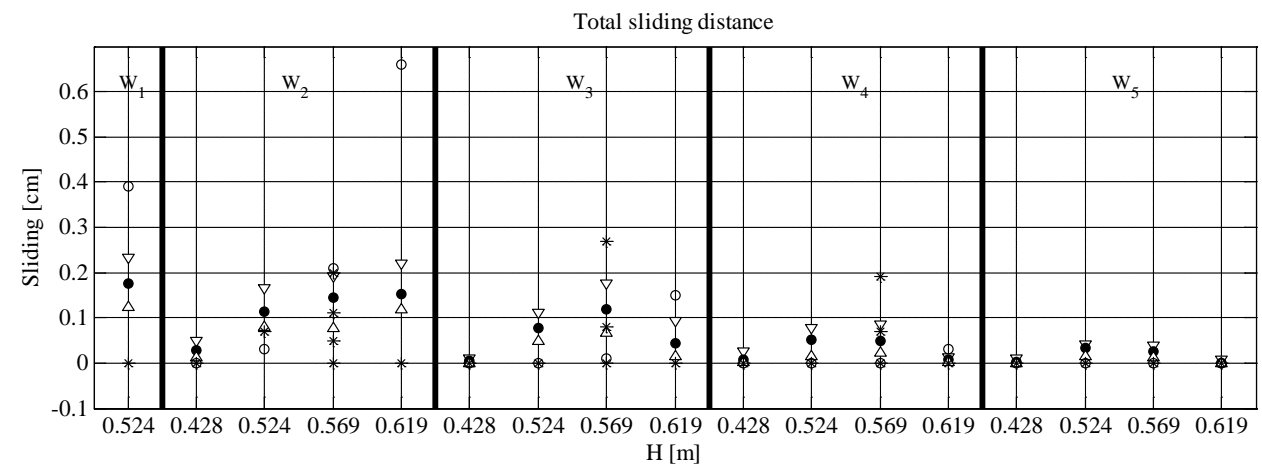

\begin{tabular}{llllllll}
\hline & Present model (max) & $\bullet$ & Present model (mean) & $\Delta$ & Present model (min) & $\circ$ & Shimosako et al. $1999 \quad * \quad$ Experiments
\end{tabular}

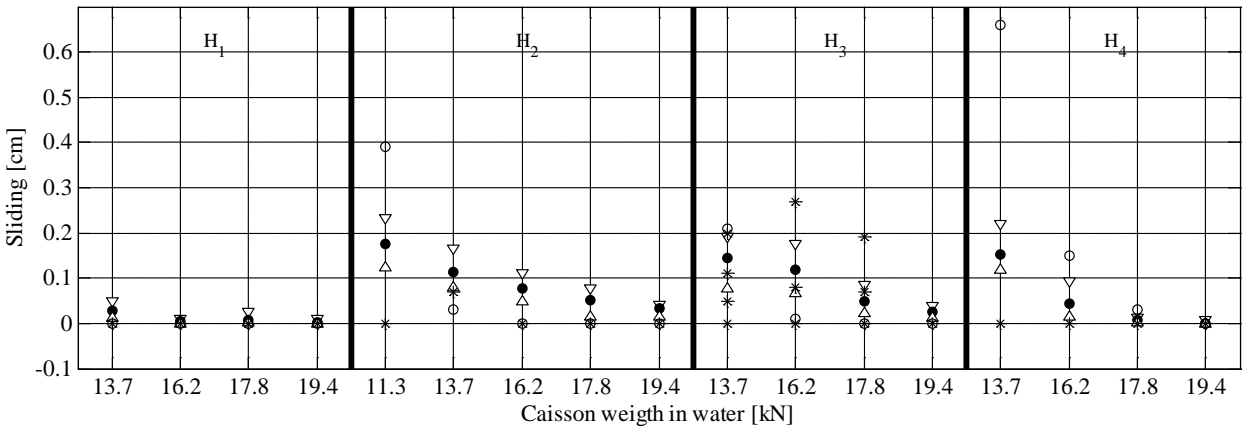

Figure 15 Sliding under breaking wave attack, comparison of measurements from physical model tests $\left(^{*}\right)$ and prediction by the present model (dots) and Shimosako et al. 1999 (circle).

Moreover, whilst the same impact maxima might theoretically correspond to different combination of the incoming wave height and water depth (Equation 30), the corresponding impact rise times will be larger for waves that are larger at the toe of the structures, which would necessarily result in a larger quasi-static load. Therefore, as far as the stability of the caisson is concerned, waves slightly higher than the breaker height corresponding to the water depth in front of the wall $H_{b r}=H_{b r}(d)$ will be more critical (and the most critical overall indeed) than those slightly lower than $H_{b r}$ since the impacts induced by the former will transmit a larger impulse. This is confirmed in Figure 15, with maximum sliding distance corresponding to wave heights ranging between $0.524 \mathrm{~m}$ and $0.569 \mathrm{~m}$, the water depth in front of the wall being $d=0.4 \mathrm{~m}$.

\section{CONCLUSIONS AND FURTHER WORK}

A non-linear dynamic model for the dynamics of caisson breakwaters subject to wave forces has been presented. Differences to previous formulations include both the generation of time-history loads to use in the analysis and the description of the non-linear features of the interaction between the superstructure and the foundation soil. In particular, impact pressure maxima and rise times are derived from data recorded at high sample rate during large scale physical model tests, which ensures a good description of peak pressure evolution in time. The effective reaction at the interface is derived by resolving in time the dynamic equation of motion in which sliding is also accounted for by means of a non-linear model assumed for the behaviour of the soil foundation. 
The model succeeds in describing the main features of the dynamic response of caisson breakwaters under both breaking and non-breaking wave attack and is fast enough to be used in probabilistic design methods as well as in fragility analysis of such kind of structures. Although resolving for the rotation of the superstructure during motion, the model doesn't account for the effect of permanent tilting angle on residual displacement of caisson breakwater. At time of writing, the authors are considering the quantification of relative importance of residual rotation of the superstructure, as a further development of the present model.

\section{ACKNOWLEDGEMENTS}

Support from HR Wallingford Ltd., HAREC S.r.I. and Studio SPERI S.r.I. is gratefully acknowledged. The first author had the opportunity to join the Port and Airport Research Institute under the JSPS post-doc programme supported by the Japanese Society for the Promotion of Science. The data used to derive relations between impact maxima and rise-times were extracted from data recorded during large-scale model tests at CIEM (LIM UPC Barcelona) under VOWS project, supported by the EC programme of Transnational Access to Major Research Infrastructure, Contract n HPRI-CT-1999-00066. Dott. Gianluca Gatto (SC Sembenelli S.r.I.) is gratefully acknowledged for his always kind and useful support in understanding and modelling of the dynamics of soil foundations.

\section{REFERENCES}

Chopra, A.K. (2001) "Dynamics of structures" ( $2^{\text {nd }}$ edition) Prentice Hall, Upper Saddle River, NJ, USA, 844 pp.

Cuomo G. and Allsop N.W.H. (2004) "Wave impacts at sea walls", Proc. of the $29^{\text {th }}$ International Conference of Coastal Engineering, Lisbon, Portugal.

Cuomo, G. (2005) "Dynamics of wave induced loads and their effects on coastal structures" PhD Thesis, University of Rome TRE.

Cuomo, G., Allsop, N.W.H., Bruce, T. and Pearson, J. (2010) "Breaking wave loads at vertical sea walls \& breakwaters” Coastal Engineering, Volume 57, Issue 4, April 2010, Pages 424-439.

Cuomo, G., Piscopia, R. and Allsop, N.W.H. (2009) "Evaluation of wave impact loads on caisson breakwaters based on joint probability of impact maxima and rise time" Coastal Engineering (in press).

de Groot, M. B.; Andersen, K. H.; Burcharth, H. F.; Ibsen, L. B.; Kortenhaus, A.; Lundgren, H.; Magda, W.; Oumeraci, H.; Richwien, W. (1996) "Foundation Design of Caisson Breakwaters". Norwegian Geotechnical Institute, Publ. No. 198, Vol. 1 and 2, Oslo, Norway.

Franco L. (1991) "Vertical breakwaters: the Italian experience and lessons from failures" Proc. of 1st Workshop of MAST G6-S-Project 2, Hannover, Germany.

Franco L. and Passoni G. (1992) "The failure of the caisson breakwater Duca D'Aosta in Naples harbour during the storm of 11th January 1987" Proc. of $2^{\text {nd }}$ Workshop of MAST G6-S-Project 2, Plymouth, UK.

Franco L. (1994) "Vertical breakwaters: the Italian experience." Special Issue on vertical breakwaters, Coastal Engineering 22:31-55. 
Gazetas G. (1990) "Foundation Vibrations" pp.553-593 in Hsai-Yang Fang "Foundation engineering handbook, $2^{\text {nd }}$ Edition" (1990), 923 pp, Kluwer Academic Publisher Group, ISBN 0-412-98891-7.

Goda, Y. (1974) "New wave pressure formulae for composite breakwater" Proc. of 14th Int. Conf. Coastal Eng., Copenhagen, Denmark, pp1702-1720. ASCE New York,

Goda Y. (1994) "Dynamic response of up-rigth breakwater to impulsive force of breaking waves" Special Issue on vertical breakwaters, Coastal Engineering 22:135-158.

Goda, Y. (2000) "Random seas and design of maritime structures", 443 pp, Advanced series on ocean engineering - vol. 15, World Scientific.

Goda, Y. and Takagi, H. (2000) "A reliability design method of caisson breakwaters with optimal wave heights" Coastal Engineering Journal, Vol. 42, No. 4, pp 357-387.

Goda, Y. (2004) "Spread parameter of extreme wave height distribution for performance-based design of maritime structures" Journal of Waterway, Port, Coastal, and Ocean Engineering Vol. 103, No. 1, pp 29-38.

Hitachi S. (1994) "Case study of breakwater damages Mutsu-Ogawara Port" Proc. of Int. Workshop of on Wave Barriers in Deep Waters. Port and Harbour Research Institute, Yokosuka, Japan, 308-331.

Hull, P. \& Müller, G. (2002) "An investigation of breaker heights, shapes and pressures" Ocean Engineering 29, pp59-79.

Kim T.-M. and Takayama T. (2003) "Computational improvement for expected sliding distance of a caissontype breakwater by introduction of a doubly truncated normal distribution", Coastal Engineering Journal, Vol. 45 No. 3 pp 387-419.

Kim T.-M., Takayama T. and Wiyawaki, Y. (2004) "Laboratory experiment of the sliding distance and tilting angle of caisson breakwater subject to wave impact", Proc. of $29^{\text {th }}$ Int. Conf. Coastal Eng., Lisbon, Portugal ASCE, pp 3762-3774.

Klammer P., Oumeraci H. and Partenscky, H. W. (1994) "Oscillatory motions and permanent displacement of caisson breakwater subject to impulsive breaking wave loads" Proc. of $24^{\text {th }}$ Int. Conf. Coastal Eng., Kobe, Japan. ASCE New York, 1255-1268.

Kortenhaus A. and Oumeraci H. (1996) "Simple model for permanent displacement of caisson breakwters under impact loads" Appendix VIII, in de Groot et al (1996) "Foundation of Caisson Breakwaters" Vol. 2: 9 pp.

Kortenhaus A. and Oumeraci H. (1998) "Classification of wave loading on monolithic coastal structures" Proc. of $26^{\text {th }}$ Int. Conf. Coastal Eng., Copenhagen, Denmark. ASCE New York, 867-880.

Ling, H. I., Cheng A. H. D., Mohri Y. and Kawabata T. (1999) "Permanent displacement of composite breakwaters subject to wave impact" J. of Waterways, Port, Coastal and Ocean Eng. 125, No.1:1-8.

Lundgren, H. (1969) "Wave shock forces: an analysis of deformations and forces in the wave and in the foundation" Proc. Symp. on Research in Wave Action. Delft Hydraulics Lab. Delft, The Netherlands, pp1-20.

Lunne, T., Robertson, P.K. and Powell, J.J.M (1997) "Cone Penetration Testing In Geotechnical Practice", Blackie Academic \& Professional, ISBN 075140393 8, 312 pp.

Loginov V. N. (1962) "Evaluation of the pressure impulse on vertical structures subject to breaking waves." Trudy Soiuzmorniiproekta (in Russian) 2:47-59. 
Loginov V. N. (1969) "Non linear oscillations of vertical breakwaters subject to wave impact loads" Trudy Soiuzmorniiproekta (in Russian) 27:67-75.

Lupoi G., Cuomo G., Shimosako K. and Takahashi S. (2007) "Wave-loads fragility assessment of caisson breakwaters under breaking and non breaking wave attack" Coastal Structures 2007 Conference, Venice, Italy (in press).

Lysmer, J. and Richart F. E. (1966) "Dynamic response of footings to vertical loading" J. of Soil Mech. and Foundations Division, ASCE 92 No. SM1:65-91.

Marinski J. R. and Oumeraci H. (1992) "Dynamic response of vertical structures to breaking wave forcesreview of the CIS design experience." Proc. of $23^{\text {rd }}$ Int. Conf. Coastal Eng., Venice, Italy. ASCE New York, 1357-1370.

Miche, R. (1944) "Mouvements ondulatoires des mers en profondeur constante on decroissante" Ann. Des Ponts et Chaussees (in French)

Minikin, R. R. (1963) "Winds, Waves and Maritime Structures" 2nd edition. London, UK: Charles Griffin.

Newmark, N. M. (1959) "A mthod of Computation for Structural Dynamics" ASCE Journal of Engineering Mechanics Division, Vol. 85, No. EM3

Nagai S. (1966) "Sliding of composite-type breakwater by breaking waves" Journal of Waterways and Harbors Division, ASCE 92 No. SM1:1-20

Oumeraci, H. (1994) "Review and analysis of vertical breakwater failures - lessons learned" Special Issue on vertical breakwaters, Coastal Engineering 22 pp3-29.

Oumeraci, H., Partenscky H. W., Kohlhase S. and Klammer P. (1992) "Impact loading and dynamic response of caisson breakwaters - Results of large-scale model tests." Proc. of $23^{\text {rd }}$ Int. Conf. Coastal Eng., Venice, Italy. ASCE New York, 1475-1488.

Oumeraci H. and Kortenhaus A. (1994) "Analysis of dynamic response of caisson breakwaters" Special Issue on vertical breakwaters, Coastal Engineering 22:159-183.

Oumeraci H., Kortenhaus A. and Klammer P. (1995) "Displacement of caisson breakwaters induced by breaking wave impacts" Proc. of Coastal Structures and Breakwaters Conf. ICE, London, paper no. 3, 14pp.

Oumeraci H., Kortenhaus A., Allsop N.W.H., De Groot M.B., Crouch R.S., Vrijling J.K. and Voortman H.G. (2001) "Probabilistic Design Tools for Vertical Breakwaters", Balkema, Rotterdam, 392 pp.

Pedersen J. (1997) "Dynamic response of caisson breakwaters subjected to impulsive wave loadng - design diagrams for static load factors" Proc. of $1^{\text {st }}$ overall project workshop, Las Palmas, Gran Canaria, Volume A 417. MAST III/PROVERBS, 22pp.

Petrashen V. I. (1956) "Action of breaking waves on vertical structures" Sbornik trudov VNIIGs (in Russian) 7:75-110.

Sainflou, G. (1928) "Essai sur les digues maritimes verticals" Annales des Ponts et Chausse'es Paris $\underline{98}, 11$, pp:5-48 (in French)

Shimosako K., Takahashi S. and Tanimoto K. (1994) "Estimating the sliding distance of composite breakwaters due to wave forces inclusive of impulsive forces", Proc. of $24^{\text {th }}$ Int. Conf. Coastal Eng., Kobe, ASCE, pp 1580-1594. 
Shimosako K. and Takahashi S. (1999) "Application of deformation-based reliability design for coastal structures" Proc. of Coastal Structures '99, Santander, Spain, Balkema, Vol. I, pp 363-371.

Smirnov G. N. and Moroz. L. R. (1983) "Oscillations of gravity protective structures of a vertical wall type" Proc. of $20^{\text {th }}$ Congress, Volume 7. 216-219.

Takahashi S., Tanimoto K. and Shimosako K. (1994) "Dynamic Response and Sliding of Breakwater Caissons against Impulsive Breaking Wave Forces" Proc. of the Wave Barriers in Deepwaters Workshop, Port and Harbour Research Institute, Yokosuka, Japan.

Takahashi S., Tsuda M., Suzuki K. and Shimosako K. (1998) "Experimental and FEM Simulation of the Dynamic Response of Caisson Wall Against Breaking Wave Impulsive Pressures" Proc. of the $26^{\text {th }}$ International Conference of Coastal Engineering, 1986-1999, ASCE.

Takahashi S., Shimosako K., Kimura K. and Suzuki K. (2000) "Typical failures of composite breakwaters in Japan" Proc. of $27^{\text {th }}$ Int. Conf. Coastal Eng. ASCE New York.

Wang Y.-Z. (2001) "Motion and stability of caisson breakwaters under breaking wave impact" Canadian Journal of Civil Engineering 28: 960-968.

Wolf J.P. (1988) "Soil-structure-interaction analysis in time domain", Prentice Hall, 416p. 


\section{Notation}

$b \quad$ minimum planar dimension of caisson breakwater

C Damping matrix

$d \quad$ water depth in front of the caisson wall

$e \quad$ depth by which the caisson is embedded in the rubble mound

E Young's modulus

$E_{100} \quad$ Young's modulus corresponding to an effective strain of $100 \mathrm{kPa}$

F $\quad$ Force vector

$F_{x} F_{y} \quad$ horizontal and vertical force respectively

$F_{q s} \quad$ quasi-static force

$F^{*} \quad$ dimensionless impact force

G shear modulus

$g \quad$ Gravity acceleration

$H \quad$ Wave height

$H_{b r} \quad$ breaker height

$H_{s} \quad$ Significant wave height

$H_{1 / 250} \quad$ Wave height at $1 / 250$ significance level

h Caisson height

K Stiffness matrix

$K_{x}, K_{y} \quad$ horizontal and vertical stiffness respectively

l maximum planar dimension of caisson breakwater

M Mass matrix

$m_{c} \quad$ caisson mass

$m_{\text {hyd }} \quad$ hydrodynamic mass

$m_{w} \quad$ mass of water displaced by the caisson

$N_{z} \quad$ number of waves in a physical model test

$P \quad$ Pressure

S Permanent displacement

$r_{0} \quad$ characteristic dimension of the equivalent circular footing

$t \quad$ Time

$T_{m} \quad$ Mean wave period 


$\begin{array}{ll}T_{0} & \text { Natural period of vibration of the structure } \\ t_{r} & \text { rise time } \\ t_{d} & \text { duration time } \\ t^{*} & \text { dimensionless impact rise-time } \\ \mathbf{u} & \text { Displacement vector } \\ \dot{\mathbf{u}} & \text { Velocity vector } \\ \ddot{\mathbf{u}} & \text { Acceleration vector } \\ W & \text { weight of caisson in water } \\ x, y, \theta & \text { horizontal, vertical and rotational axes } \\ x_{A}, y_{A} & \text { coordinates of the centre of rotation of the caisson } \\ x_{g} & \text { lever arm of the gravitational load } \\ x_{L}, y_{L} & \left.\text { lever arm of the vertical ( } F_{y}\right) \text { and horizontal }\left(F_{x}\right) \text { forces respectively } \\ \alpha & \text { empirical coefficient } \\ \mu_{s} & \text { static friction coefficient } \\ \mu_{d} & \text { dynamic friction coefficient } \\ \rho_{w} & \text { density of water } \\ \rho_{s} & \text { density of soil foundation } \\ v & \text { Poisson's ratio } \\ \sigma_{v}^{\prime} & \text { effective strain } \\ \sigma_{v 0}^{\prime} & \text { reference effective strain }\end{array}$

